\title{
${ }^{\partial}$ Regional Climate Responses in East Asia to the Black Carbon Aerosol Direct Effects from India and China in Summer
}

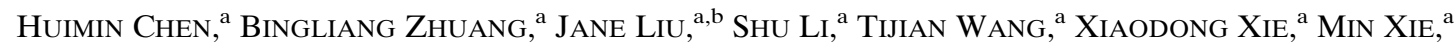 \\ Mengmeng Li, ${ }^{a}$ AND Ming ZHAO ${ }^{\mathrm{a}}$ \\ ${ }^{\text {a }}$ School of Atmospheric Sciences, CMA-NJU Joint Laboratory for Climate Prediction Studies, Jiangsu Collaborative Innovation \\ Center for Climate Change, Nanjing University, Nanjing, China, ${ }^{\mathrm{b}}$ Department of Geography and Planning, University of Toronto, \\ Toronto, Canada
}

(Manuscript received 3 October 2019, in final form 5 July 2020)

\begin{abstract}
Black carbon (BC) aerosol is a significant and short-lived climate forcing factor. Here, the direct effects of $\mathrm{BC}$ emissions from India (IDBC) and China (CNBC) are investigated in East Asia during summer using the state-of-the-art regional climate model RegCM4. In summer, IDBC and CNBC account for approximately $30 \%$ and $46 \%$ of the total BC emissions in Asia, respectively. The total BC column burden from the two countries and corresponding TOA effective radiative forcing are $1.58 \mathrm{mg} \mathrm{m}^{-2}$ and $+1.87 \mathrm{~W} \mathrm{~m}^{-2}$ in East Asia, respectively. The regional air temperature increases over $0.3 \mathrm{~K}$ at maximum and precipitation decreases $0.028 \mathrm{~mm}^{-1 a y}{ }^{-1}$ on average. Individually, IDBC and CNBC each can bring about rather different effects on regional climate. IDBC can result in a cooling perturbation accompanied by a substantially increased cloud amount and scattering aerosol loading, resulting in a complex response in the regional precipitation, while CNBC can lead to regional warming, and further induce a local flood in northern China or drought in southern China depending on the opposite but significant circulation anomalies. CNBC plays a dominant role in modulating the regional climate over East Asia due to its higher magnitude, wider coverage, and stronger climate feedback. The direct effect of the total BC from both countries is not a linear combination of that of IDBC and CNBC individually, suggesting that the regional climate responses are highly nonlinear to the emission intensity or aerosol loading, which may be greatly related to the influences of the perturbed atmospheric circulations and climate feedback.
\end{abstract}

KEYWORDS: Numerical analysis/modeling; Regional models; Aerosol radiative effect; Aerosols/particulates

\section{Introduction}

Black carbon (BC) aerosols can significantly impact climate change at both regional and global scales via the direct, indirect, and snow albedo effects (Twomey 1974; Albrecht 1989; Menon et al. 2002; Lau et al. 2006; Forster et al. 2007; Randles and Ramaswamy 2008; Zhuang et al. 2010; Wang et al. 2011; Wilcox 2012). The BC potential warming effect plays an important role in global and regional warming (Myhre et al. 2013). The convergence and upward motion anomalies caused by $\mathrm{BC}$ can result in a more unstable stratification of the atmosphere (Randles and Ramaswamy 2008; Zhuang et al. 2013), which further leads to changes in thermal-dynamic processes and the hydrologic cycles (Menon et al. 2002; Lau and Kim 2006; Bollasina et al. 2008; Wu et al. 2008; Zhuang et al. 2018, 2019).

$\mathrm{BC}$ aerosols are known to influence the regional climate over East Asia in summer to a large degree (Guo et al. 2013; Zhou et al. 2014; Song et al. 2014; Wang et al. 2015; Zhuang et al. 2018) through affecting Earth's radiation budget, which is referred to as the $\mathrm{BC}$ direct effect. According to both observation and simulation, $\mathrm{BC}$ reduces the incoming shortwave radiation that reaches the surface more effectively than scattering aerosols (Forster et al. 2007; Boucher et al. 2013; Bond

¿ Denotes content that is immediately available upon publication as open access.

Corresponding author: Bingliang Zhuang, blzhuang@nju.edu.cn et al. 2013; Zhuang et al. 2014; Wang et al. 2015; K. Li et al. 2016). BC imposes a positive direct radiative forcing (DRF) at the top of the atmosphere (TOA), ranging from the order of $10^{-1} \mathrm{~W} \mathrm{~m}^{-2}$ on a global scale to $10^{0} \mathrm{~W} \mathrm{~m}^{-2}$ in polluted urban areas (Zhuang et al. 2013; Boucher et al 2013; Myhre et al. 2013; Zhuang et al. 2014). The regional mean of BC DRF was estimated to be $+0.81 \mathrm{~W} \mathrm{~m}^{-2}$ over East Asia (Zhuang et al. 2013) and $+1.22 \mathrm{~W} \mathrm{~m}^{-2}$ over China (K. Li et al. 2016), while the global mean is assessed as $+0.71 \mathrm{~W} \mathrm{~m}^{-2}$ (Bond et al. 2013). Therefore, the $\mathrm{CO}_{2}$ greenhouse effect, which is offset by the negative TOA DRF of scattering aerosols (Kiehl and Briegleb 1993), could be enhanced by the BC direct effect (Wang et al. 2015; Zhuang et al. 2018). The BC-induced radiation perturbation alters the regional or global climate because the perturbation can impact the thermodynamic conditions and hydrological cycle (Lohmann et al. 2000; Kristjánsson 2002; Qian et al. 2003; Cook and Highwood 2004; Wu et al. 2008; Bollasina et al. 2008; Zhuang et al. 2010, 2013). Moreover, the strongest and most extensive radiative forcing by both scattering and absorbing aerosols in the Northern Hemisphere occurs in summer (Ghan et al. 2001; Zhang et al. 2008, 2009; Yu et al. 2013; Zhuang et al. 2018), and East Asia experiences heavy rainfall in summer because of the Asian monsoon. As a result, the weather and climate system are more sensitive to aerosol effects during this season (Zhang et al. 2009). Lau et al. (2006), Lau and Kim (2006), and Meehl et al. (2008) suggested that increased absorbing aerosols (including BC) could intensify the circulation of the Indian summer monsoon with the advancing rainy season, thus leading to the increased precipitation 
over South Asia and decreased precipitation over East Asia. Manoj et al. (2011) indicated that BC can also be conducive to the Indian summer monsoon transition from break to active spells. Furthermore, Wang et al. (2015) and Zhuang et al. (2018) implied that BC can favor the circulation development of East Asian summer monsoon, and further result in regional droughts and floods. Additionally, the atmospheric stability can be modified under the BC direct effect (Randles and Ramaswamy 2008; Wu et al. 2008; Zhuang et al. 2013; Ding et al. 2016; S. Li et al. 2016). All these studies have addressed the significant role of $\mathrm{BC}$ in modulating regional climate, especially in high $\mathrm{BC}$ regions (e.g., China and India) or in sensitive climate systems (e.g., the summer monsoon).

China has frequently experienced episodes of severe air pollution over the recent decades because of rapid industrialization and urbanization (Yang et al. 2018), which are accompanied with substantially increased emissions of aerosols including BC (Qin et al. 2001; Cao et al. 2006; Zhang et al. 2009; Li et al. 2017). Observations in China showed that the annual mean of surface $\mathrm{BC}$ concentration was up to $10 \mu \mathrm{g} \mathrm{m}^{-3}$ in urban areas and up to $4 \mu \mathrm{g} \mathrm{m}^{-3}$ at rural sites (Zhang et al. 2008, 2012). BC can considerably contribute to haze pollution episodes (Ding et al. 2016). Observations in India, where national BC emissions are second highest among Asian countries, suggested that BC loadings there could reach $15 \mu \mathrm{g} \mathrm{m}^{-3}$ in summer at urban sites despite a wide range of spatial and temporal variations (Babu and Moorthy 2002; Rai et al. 2002; Tripathi et al. 2005; Pant et al. 2006). Furthermore, BC in the Indo-Gangetic Plain (IGP) of northern India, a regional pollution hotspot, strengthened the environmental sensitivity of the domain (Gautam et al. 2011; Giles et al. 2011; Praveen et al. 2012; Lal et al. 2013). The seasonal mean of surface $\mathrm{BC}$ concentration in summer is illustrated in Fig. 1, showing substantially high BC (exceeding $8 \mu \mathrm{g} \mathrm{m}^{-3}$ ) in China and India. Owing to their potential effects on global warming and regional air quality, $\mathrm{BC}$ emissions must be reduced. $\mathrm{BC}$ emissions from China and India have different temporal and spatial variations, and their BC DRF and associated climate responses are also different, which in turn changes the spatial pattern of forcing due to other aerosol species in different ways. Notably, the climate effects may not be entirely dependent on BC loadings (Sadiq et al. 2015), which can bring large uncertainty in estimating the climate changes induced by BC emissions in different regions. Although several studies have focused on the direct effect of BC over East Asia, few have addressed these differences in the climate responses, which is necessary for quantifying climate change associated with aerosols in present and future.

To address the research gap, in this study, we consider the climate responses in East Asia to $\mathrm{BC}$ emissions from India (IDBC) and China (CNBC), two Asian countries with the highest $\mathrm{BC}$ emission levels in the world. We examine the responses through analysis of the BC column burden and effective radiative forcing (ERF), using a recently updated version of the regional climate model RegCM4 (Giorgi et al. 2012) combined with the Multiresolution Emission Inventory for China (MEIC) (Li et al. 2017). In the following, the model and simulation experiments are described in section 2. The simulation results are shown and discussed in detail in section 3 . Finally, the conclusions are provided in section 4.

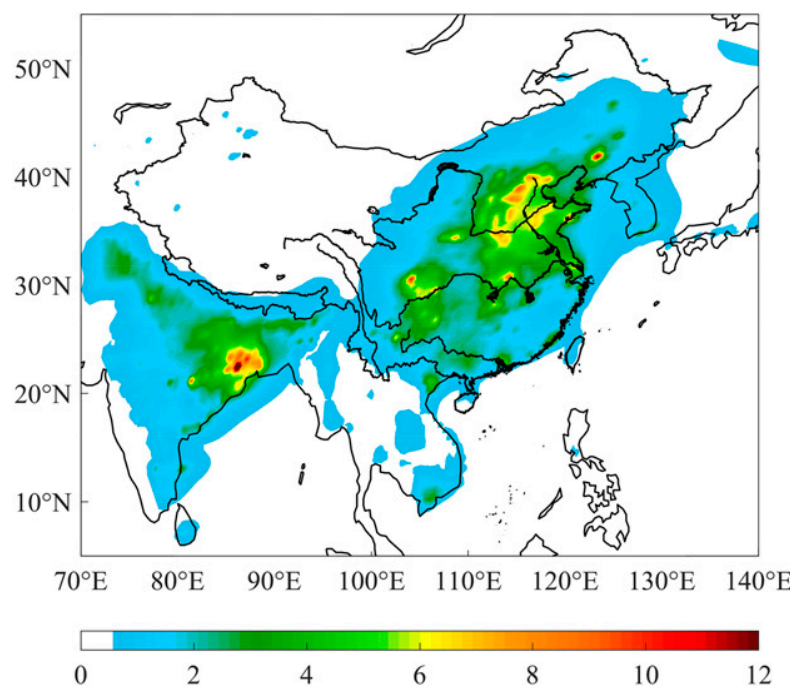

FIG. 1. Seasonal mean of surface BC concentrations $\left(\mu \mathrm{g} \mathrm{m}^{-3}\right)$ over the study domain.

\section{Methodology}

\section{a. Description of the regional climate model RegCM4}

Because of their higher spatial resolutions, regional climate models are more capable of capturing small-scale characteristics of the climate than global climate models (Denis et al. 2002). In this study, we employ the latest version of the regional climate model RegCM4 (Solmon et al. 2012; Giorgi et al. 2012), which has been widely used to investigate the interactions between aerosols, climate, and biogeochemical cycles (Zhou et al. 2014; Yin et al. 2015; Z. Q. Li et al. 2016; Zhuang et al. 2018, 2019; Xie et al. 2020).

RegCM4 provides a much more comprehensive description on air pollutants than RegCM3, including a gas phase chemistry module with the Carbon Bond Mechanism, version $\mathrm{Z}$ (CBMZ; Shalaby et al. 2012) and a volatility basis set model (VBS; Yin et al. 2015) to address trace gases and secondary organic aerosols, respectively. In addition to the scheme of Qian et al. (2001) used in this research to address sulfate aerosols, which can describe the chemical conversion between $\mathrm{SO}_{2}$ and sulfate and requires less computational cost, the current version has also coupled with a thermodynamic equilibrium model (ISORROPIA; Fountoukis and Nenes 2007; Z. Q. $\mathrm{Li}$ et al. 2016) to address inorganic aerosols (Z. Q. Li et al. 2016). A radiative transfer package from the National Center for Atmospheric Research (NCAR) Community Climate Model, version 3 (CCM3; Kiehl et al. 1996) is applied for the aerosol direct radiative forcing investigation. Furthermore, with the latest schemes equipped (such as the indirect effect of aerosols, land surface, and boundary layer), RegCM4 can simulate nearly all climate effects of natural and anthropogenic aerosols (Z. Q. Li et al. 2016).

\section{b. The climate effects of aerosols}

The direct effect of aerosols, which is generally termed as the direct radiative forcing, is highly dependent on the 
wavelength-dependent aerosol optical depth (AOD), which is estimated in RegCM4 for carbonaceous aerosols, including BC and primary organic carbon (POC; Kasten 1969), and sulfate (Kiehl et al. 2000). The indirect effect of aerosols is addressed by empirical schemes, which are applied to calculate the cloud drop number concentration, the effective radius, and the autoconversion rate from cloud water to rainwater, all of which are estimated in RegCM4 for the scattering aerosols, including POC and sulfate (Gultepe and Isaac 1999; Hansen et al. 2005; Kristjánsson 2002; Martin et al. 1994; Chen and Cotton 1987; Liou and Ou 1989; Boucher and Lohmann 1995). Detailed descriptions, especially the corresponding formulas and parameters, can be found in Wang et al. (2015).

\section{c. Emissions and experimental settings}

An updated BC emission inventory from 2010 (http:// www.meicmodel.org) compiled by Tsinghua University ( $\mathrm{Li}$ et al. 2017) is employed to provide the anthropogenic aerosol emissions. BC emissions are spatially inhomogeneous and high in northeastern India and northeastern and southwestern China, which is mainly attributed to four sectors: residential (dominant), industry, energy, and transportation (Zhuang et al. 2019). The monthly average emission over Asia during summer is $0.26 \mathrm{Tg}$, of which CNBC accounts for $46 \%(0.12 \mathrm{Tg})$ and IDBC for $30 \%(0.084 \mathrm{Tg})$.

The model domain is illustrated in Fig. 1, with its center at $29.5^{\circ} \mathrm{N}, 106.0^{\circ} \mathrm{E}$, and horizontal resolution of $60 \mathrm{~km}$. The model has $18 \sigma$-coordinate layers in the vertical direction from the surface to $50 \mathrm{hPa}$. The National Centers for Environmental Prediction (NCEP) reanalysis data (NNPR2; http://clima-dods. ictp.it/data/regcm4//NNRP2/) and the weekly mean product of National Ocean and Atmosphere Administration's (NOAA) Optimum Interpolated Sea Surface Temperature dataset (OISST; https://psl.noaa.gov/data/gridded/data.noaa.oisst.v2.html) are implemented to drive the model for initial and time-dependent boundary conditions, and the same time-dependent SST field is used in all experiments to exclude the its influence when estimating the BC climate effects. The climatological chemical data from the Model of Ozone and Related Chemical Tracers (MOZART), which is a global chemical transport model, is applied to provide the initial and boundary conditions of aerosols (Horowitz et al. 2003; Emmons et al. 2010).

To understand the climate responses in East Asia to the direct effects of $\mathrm{BC}$ from different source regions, four sets of numerical experiments (one control and three sensitivity experiments, shown in Table 1) are carried out. Notably, although the current version of RegCM4 has incorporated chemical and physical processes that are essential to deal with nearly all trace gases and aerosol species as mentioned in section $2 \mathrm{a}$, including more species requires more expensive computational costs. As a result, only sulfate aerosols (as the main scattering aerosol), BC, and POC (carbonaceous aerosol) are considered in our experiments. The combined (direct plus indirect) effects of both sulfate aerosols and POC as well as the direct effect of $\mathrm{BC}$ are taken into account in all the numerical simulations using different $\mathrm{BC}$ emission inventories when estimating a given region's $\mathrm{BC}$ direct radiative forcing and climate effects. Experiment 1 is the control run, which does not
TABLE 1. Numerical experimental setup in this study.

\begin{tabular}{lc}
\hline Experiments & \multicolumn{1}{c}{ Climate effects } \\
\hline Exp. 1 & $\begin{array}{r}\text { Control run with BC direct effect and all } \\
\text { other aerosol effects in the study domain } \\
\text { No BC direct effect in India }\end{array}$ \\
Exp. 2 & No BC direct effect in China \\
Exp. 3 & No BC direct effect in China and India \\
Exp. 4 & \\
\hline
\end{tabular}

switch off the BC emissions (the emission flux is set to 0 ) of any regions in the study domain. Experiments $2-4$ switch off IDBC, $\mathrm{CNBC}$, and the total $\mathrm{BC}$, respectively. The definition of a given geographical region (India and China specifically) is strictly based on the country borders when identifying a switched-off emission grid. All the numerical simulations have been performed from November 1995 to February 2007 with a spinup period of 3 months, and only the results of summer [JuneAugust (JJA)] are analyzed. The direct effect of BC on the regional climate from a given region can therefore be defined as the differences between the control experiment and the associated sensitivity experiment, which are climatologically averaged for the integration period. A two-sided Student's $t$ test is conducted (based on the monthly average data) to assess the statistical significance of the difference between each of the two experiments to exclude the internal variability generated by the climate model.

\section{Results and discussion}

\section{a. Model validation}

The performance of RegCM4 in simulating regional climate over the region of Asia has been evaluated in previous studies temporally in monthly and annual spans and spatially at the surface and in the entire troposphere (Wang et al. 2010; Sun et al. 2012; Nair et al. 2012; Zhou et al. 2014; Yin et al. 2015; Z. Q. Li et al. 2016; Das et al. 2016; Zhuang et al. 2018). Overall, RegCM4 can generally capture the typical features of the magnitudes and variations of meteorological fields, although there remain some discrepancies against observations.

The ability of RegCM4 to reproduce the BC concentration and optical depth has been evaluated via the comparisons with the observations from sites (AERONET, ARFINET) and satellite instruments (MODIS, MISR), as well as simulations from a global chemistry model (GEOS-Chem), all of which indicate that RegCM4 can well simulate the magnitude, spatial distribution, and seasonality of BC over East Asia and South Asia (Nair et al. 2012; Ji et al. 2015; K. Li et al. 2016; Zhuang et al. 2018, 2019). For more confidence, the annual mean of POC and sulfate concentrations are compared between simulations and observations in this study (Fig. 2; see also Table 2). The observations are from Zhang et al. $(2008,2012)$ and have been widely applied as the representative site values (Fu et al. 2012; Lou et al. 2014; Fu et al. 2016; Kasoar et al. 2016). The annual means of the simulated POC and sulfate at these sites are 9.10 and $22.28 \mu \mathrm{g} \mathrm{m}^{-3}$, both of which are slightly lower than the observations. The linear correlation coefficients $(r)$ between 


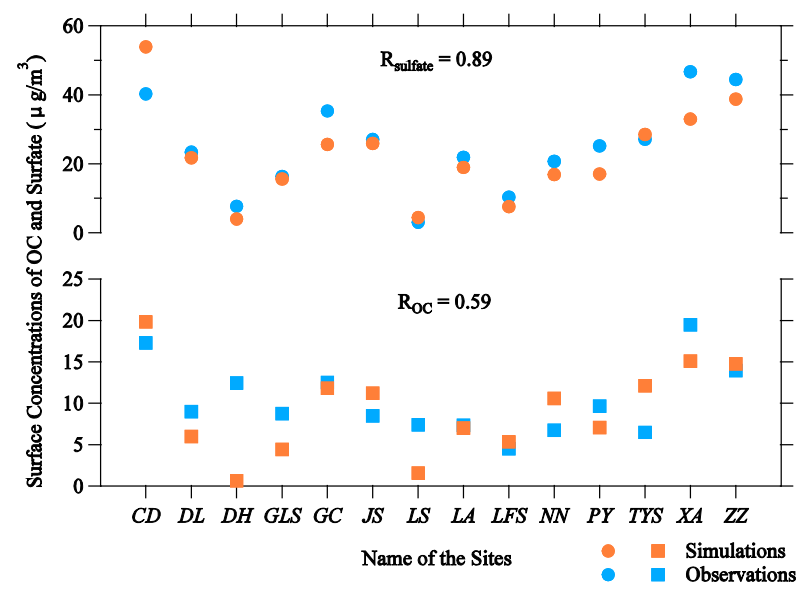

FIG. 2. Comparisons of the annual mean POC and sulfate between the simulations and observations at various sites in China (see Table 2 for site information).

the simulated and observed POC and sulfate are $0.59(p<0.05)$ and $0.89(p<0.05)$, respectively. The simulations are slightly lower than the observations at most sites except for POC at Dunhuang and Lhasa. This underestimation is possibly attributed to a missing source in the inventories associated with high carbonaceous aerosols emission ratios rather than to the model deficiency ( $\mathrm{Fu}$ et al. 2012; K. Li et al. 2016). Generally, the seasonality and magnitude of POC and sulfate in East Asia are essentially captured by RegCM4. High POC and sulfate concentrations, similar to BC, mainly appear in northern (Gucheng), southwestern (Chengdu), and central (Xi'an and Zhengzhou) China, which are related to the high emission rates (Lu et al. 2011; Fu et al. 2012; Zhao et al. 2013; Zhou et al. 2014; Zhuang et al. 2018). This comparison supplements the previous RegCM4 validations on scattering aerosols (Sun et al. 2012; Nair et al. 2012; Solmon et al. 2012; Ji et al. 2015) using retrieved satellite (MODIS, MISR) and GOCART data.

\section{b. Column burden and effective radiative forcing of $B C$}

The summertime distributions of the column burden are shown for experiments with different source regions in Fig. 3. High column burdens appear in northeastern India, and southwestern and central to northern China, with a maximum exceeding $7 \mathrm{mg} \mathrm{m}^{-2}$. This spatial distribution generally agrees well with that of emission levels in Li et al. (2017). Corresponding to the emission level, the CNBC column burden is dominant, the regional mean of which is 1.5 times higher compared to the IDBC column burden in the study domain. However, IDBC presents a higher maximum (up to $8 \mathrm{mg} \mathrm{m}^{-2}$ ) in northern India. This minor inconsistency of the column burden to the emission level results from the strong cyclone in northeastern India during summer when the prevailing south winds converge with westerlies under the orographic barrier effect of the Himalayas and help confine the monsoon within the India subcontinent (Ji et al. 2015). The column burden in Fig. 3 is approximately 0.2-5.2 times higher than that in previous studies (Qian et al. 2003; Chang and Park 2004; Wu et al. 2008; Zhang et al. 2009; Zhuang et al. 2009) on account of various inventories used in these studies. The changes
TABLE 2. Basic information of the BC observation sites shown in Fig. 2.

\begin{tabular}{llcc}
\hline \hline Site code & \multicolumn{1}{c}{ Name } & Location $\left({ }^{\circ} \mathrm{N},{ }^{\circ} \mathrm{E}\right)$ & Type \\
\hline CD & Chengdu & $30.65,104.04$ & Urban \\
DL & Dalian & $38.90,121.63$ & Urban \\
DH & Dunhuang & $40.15,94.68$ & Rural \\
GLS & Gaolanshan & $36.00,105.85$ & Rural \\
GC & Gucheng & $39.13,115.80$ & Rural \\
JS & Jinsha & $29.63,114.20$ & Rural \\
LAS & Lhasa & $29.67,91.13$ & Urban \\
LA & Linan & $30.30,119.73$ & Rural \\
LFS & Longfengshan & $44.73,127.60$ & Rural \\
NN & Nanning & $22.83,108.35$ & Urban \\
PY & Panyu & $23.00,113.35$ & Urban \\
TYS & Taiyangshan & $29.17,111.71$ & Rural \\
XA & Xian & $34.43,108.97$ & Urban \\
ZZ & Zhengzhou & $34.78,113.68$ & Urban \\
\hline
\end{tabular}

in the shortwave heating rate (SWHR; Fig. 3) in the lower troposphere due to IDBC, $\mathrm{CNBC}$, and the total $\mathrm{BC}$ are remarkable (over $10^{-6} \mathrm{~K} \mathrm{~s}^{-1}$ if averaged from the surface to $840 \mathrm{hPa}$ ). Higher $\mathrm{BC}$ loading can lead to faster heating rates in the lower troposphere through absorbing more solar radiation, and to considerably more SWHR where the loading is higher.

BC can exert a positive DRF at the TOA and a negative DRF at the surface. The ERF (the net solar flux difference between perturbed and control experiments) values at the TOA and surface induced by BC from different source regions are illustrated in Fig. 4, which presents similar spatial features to the corresponding column burden in Fig. 3. Strong ERF of the total BC appears in northeastern India, the Qinghai Tibet Plateau region (QTP) and surroundings, northern to southwestern China, and the middle to downstream reaches of the Yangtze River, with peaks of $+10.00 \mathrm{~W} \mathrm{~m}^{-2}$ at the TOA and $-15.00 \mathrm{~W} \mathrm{~m}^{-2}$ at the surface (SRF). The ERF at the TOA caused by the total BC is strong over the western and eastern QTP where the column burden is low, which is possibly due to different surface albedo according to Zhuang et al. (2014), who conducted sensitivity tests and subsequently implied that a higher surface albedo could lead to a stronger and positive ERF. In the Sichuan Basin, the ERF at the TOA appears less substantial than its surroundings in east despite the high column burden, which is related to the increased cloud amount and strengthened convergence (Figs. 6 and 8).

CNBC and IDBC have comparable ERF with different spatial distributions. The IDBC-induced ERF at the TOA is strongly positive over northeastern India (peaking at $+11.84 \mathrm{~W} \mathrm{~m}^{-2}$ ) but negative over central to southern China. A significantly positive ERF induced by CNBC occurs in northern China (maximum of $+8.68 \mathrm{~W} \mathrm{~m}^{-2}$ ), as well as in the middle to downstream reaches of the Yangtze River (ranging from +4.00 to $+8.00 \mathrm{~W} \mathrm{~m}^{-2}$ ). The $\mathrm{ERF}$ at the surface resembles a similar distribution to that at the TOA, but with a larger magnitude and an opposite sign.

Table 3 summarizes the regional mean column burden and ERF over East Asia $\left(20^{\circ}-45^{\circ} \mathrm{N}, 100^{\circ}-130^{\circ} \mathrm{E}\right)$ and its subregions with high emissions in China including northern China $\left(30^{\circ}-45^{\circ} \mathrm{N}\right.$, $\left.108^{\circ}-120^{\circ} \mathrm{E}\right)$, southeastern China $\left(20^{\circ}-30^{\circ} \mathrm{N}, 110^{\circ}-120^{\circ} \mathrm{E}\right)$, and 

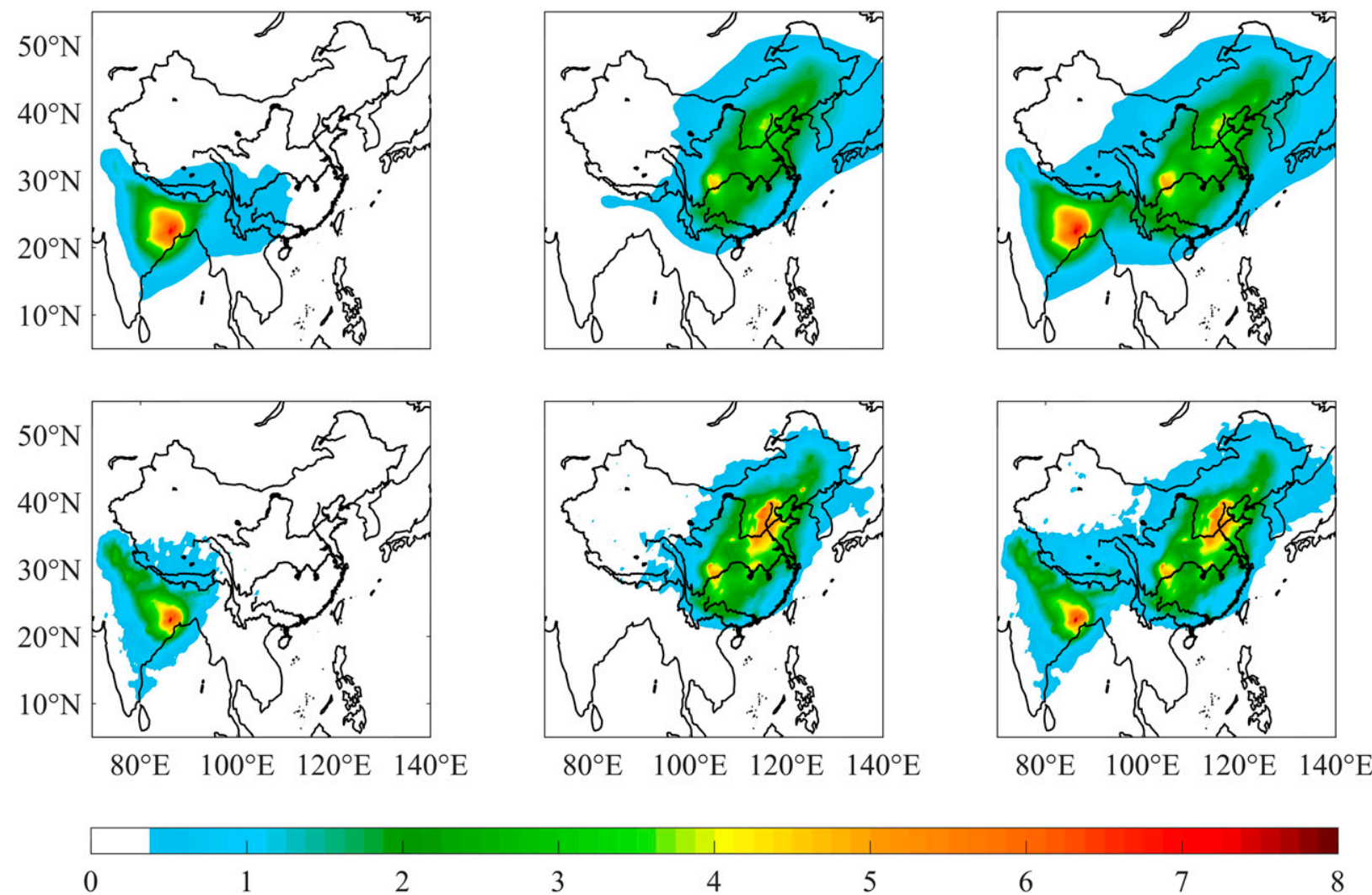

FIG. 3. Seasonal means of (top) BC column burden $\left(\mathrm{mg} \mathrm{m}^{-2}\right)$ and (bottom) SWHR $\left(10^{-6} \mathrm{~K} \mathrm{~s}^{-1}\right)$ averaged from the surface to $840 \mathrm{hPa}$ in response to (left) IDBC, (center) CNBC, and (right) the total BC.

southwestern China $\left(25^{\circ}-35^{\circ} \mathrm{N}, 100^{\circ}-110^{\circ} \mathrm{E}\right)$ are summarized for $\mathrm{BC}$ emissions from different source regions. Over East Asia, the means of the total BC column burden, and corresponding ERF at the TOA and surface are $1.501 \mathrm{mg} \mathrm{m}^{-2},+1.925 \mathrm{~W} \mathrm{~m}^{-2}$, and $-4.768 \mathrm{~W} \mathrm{~m}^{-2}$, respectively. A higher column burden is from CNBC $\left(1.312 \mathrm{mg} \mathrm{m}^{-2}\right)$, which is approximately an order of magnitude higher than that from IDBC $\left(0.169 \mathrm{mg} \mathrm{m}^{-2}\right)$. However, the ratio of the instantaneous DRF at the surface to the column burden is high from IDBC $\left(-7.526 \mathrm{~W} \mathrm{mg}^{-1}\right)$, approximately twice as high than that from CNBC $\left(-3.804 \mathrm{~W} \mathrm{mg}^{-1}\right)$, suggesting the nonlinearity that strong responses can produce despite the relatively low column burden and disperse spatial distribution. Individually for $\mathrm{BC}$ emissions from each of the defined subregions, the column burden of CNBC is the highest in northern China, followed by southwestern China and southeastern China, while the column burden of IDBC is the lowest in northern China, followed by southeastern China and southwestern China in ascending order. Generally, a higher column burden correlates well to a stronger ERF, and the surface ERF is approximately 2-3 times stronger than the TOA ERF. Additionally, IDBC can cause a negative (or slightly positive) ERF at the TOA in all areas, which is inconsistent with the merely direct effect of BC. The feedback of increased cloud cover and scattering aerosols may account for the exceptions, which are able to compensate for the regional warming induced by $\mathrm{BC}$.
Various modeling and observational studies have conducted on the DRF of BC aerosols over East Asia. Wu et al. (2008), Zhuang et al. (2013), and K. Li et al. (2016) indicated that the annual mean DRF is approximately $+0.32,+0.81$, and $+1.46 \mathrm{~W} \mathrm{~m}^{-2}$ at the TOA under all-sky conditions based on different emission inventories (1.01, 1.81, and $1.84 \mathrm{Tg} \mathrm{yr}^{-1}$, respectively). Zhuang et al. (2018) suggested that the seasonal mean DRF in summer is +1.85 and $-2.65 \mathrm{~W} \mathrm{~m}^{-2}$ at the TOA and surface over East Asia, respectively. Regionally, Zhuang et al. (2019) stated that the mean DRF over northern China, southeastern China, and the Sichuan Basin is $+2.25,+1.45$, and $+1.63 \mathrm{~W} \mathrm{~m}^{-2}$ at the TOA, and $-8.07,-5.22$, and $-4.67 \mathrm{~W} \mathrm{~m}^{-2}$ at the surface, respectively. Additionally, the DRF of absorbing aerosols is approximately $+4.5 \mathrm{~W} \mathrm{~m}^{-2}$ as estimated by Zhuang et al. (2014) based on the observation in Nanjing, China, which is $+3.782 \mathrm{~W} \mathrm{~m}^{-2}$ in this study. Overall, the $\mathrm{ERF}$ of the total $\mathrm{BC}$ in this study are commensurate with these documented values although only India and China are considered as source regions, likely due to the fact that the $\mathrm{BC}$ emission level in other regions, such as Southeast Asia, is much lower in summer (Li et al. 2017). The results can quantify fractional contributions of different source regions to the total DRF in East Asia.

\section{c. The direct effect of BC on climate}

$\mathrm{BC}$ can significantly affect the atmospheric thermodynamic field and hydrologic cycle by absorbing solar radiation. The 

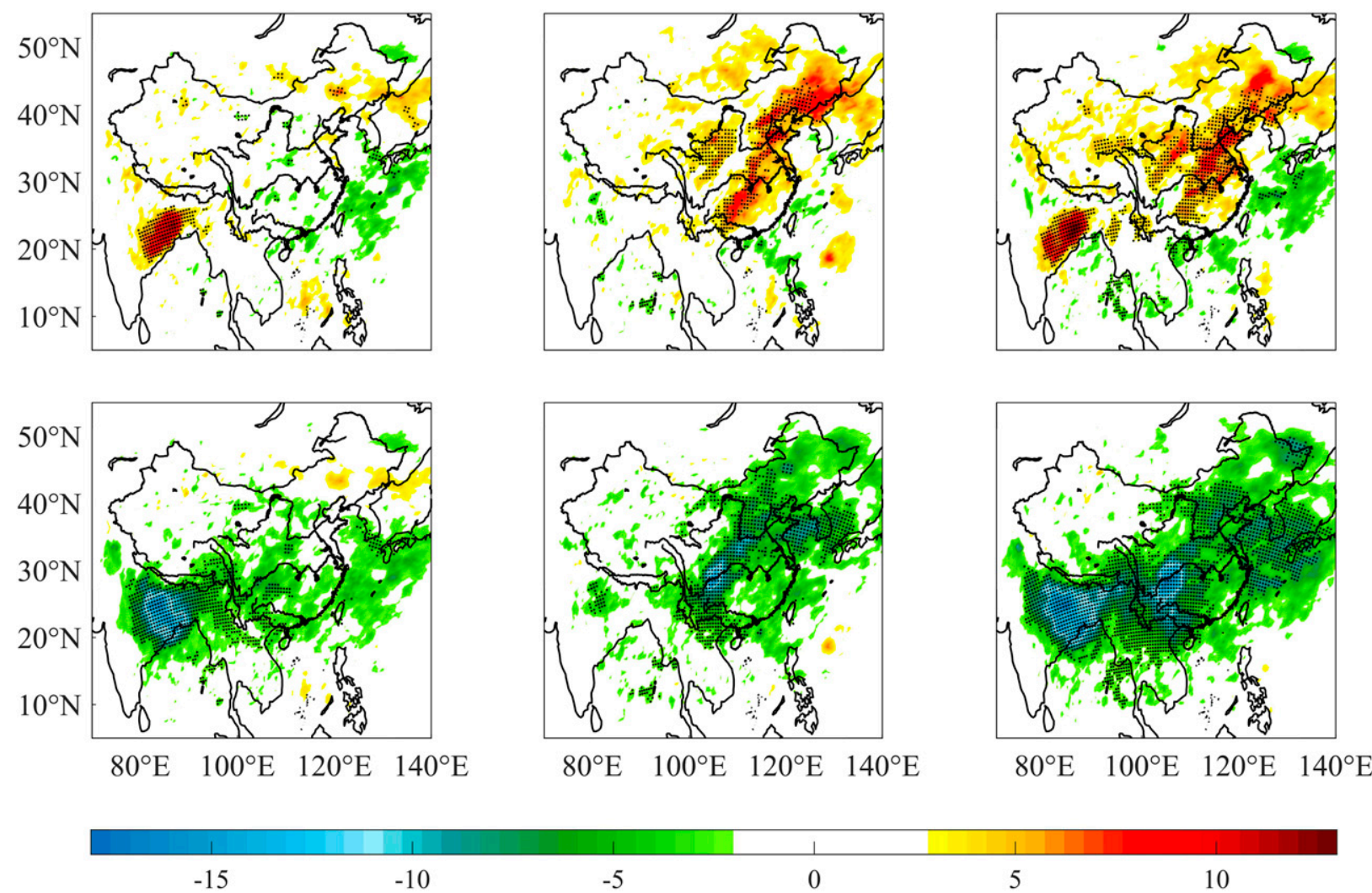

FIG. 4. Seasonal mean of BC ERF ( $\mathrm{W} \mathrm{m}^{-2}$ ) at (top) TOA and (bottom) surface in response to (left) IDBC, (center) CNBC, and (right) the total BC. The black dots (for the forcing) indicate the $90 \%$ confidence levels from the Student's $t$ test.

regional climate responses to $\mathrm{BC}$ were assessed using the results from Exp. 2, 3, and 4, respectively, minus those from Exp. 1. All figures in this section illustrate the net effects with consideration of the feedbacks of the regional climate system to the BCDRF. In the following, we provide further discussion on these effects from thermal, dynamic, and hydrological perspectives.

\section{1) THERMAL FIELD RESPONSES TO BC}

Figure 5 shows the responses in near-surface air temperature (TAS) to different region-emitted BC DRF. CNBC is in favor of regional warming mainly in eastern and southern China and the QTP, while IDBC induces regional cooling in southwestern and central China and northern India, corresponding to the strongly negative ERF at the surface. The strongest TAS response in China to the BC DRF from each of the source regions is approximately equal in magnitude $(0.3 \mathrm{~K})$. The total $\mathrm{BC}$ leads to a TAS difference ranging from -0.6 to $0.4 \mathrm{~K}$, with the maximum in eastern China and minimum in northern India. Also, similarities in the distribution of the TAS changes due to the total BC to those induced by CNBC are found in East Asia;

TABLE 3. Regional means of the BC column burden and direct radiative forcing (ERF; $\mathrm{W} \mathrm{m}^{-2}$ ) in southeast, southwest, and northern China and over East Asia, responding to BC emissions from India only, from China only, and from both countries. [SEC is southeastern China $\left(110^{\circ}-120^{\circ} \mathrm{E}, 20^{\circ}-30^{\circ} \mathrm{N}\right)$, SWC is southwestern China $\left(100^{\circ}-110^{\circ} \mathrm{E}, 25^{\circ}-35^{\circ} \mathrm{N}\right)$, NC is northern $\mathrm{China}^{\circ}\left(108^{\circ}-120^{\circ} \mathrm{E}, 30^{\circ}-45^{\circ} \mathrm{N}\right)$, and EA is East Asia $\left(100^{\circ}-130^{\circ} \mathrm{E}, 20^{\circ}-50^{\circ} \mathrm{N}\right)$. SRF indicates at the surface, and TOA at the top of the atmosphere.

\begin{tabular}{|c|c|c|c|c|c|}
\hline & Emission expt & SEC & SWC & $\mathrm{NC}$ & EA \\
\hline \multirow[t]{3}{*}{$\mathrm{BC}$ burden $\left(\mathrm{mg} \mathrm{m}^{-2}\right)$} & India & 0.213 & 0.406 & 0.135 & 0.169 \\
\hline & China & 1.073 & 2.077 & 2.221 & 1.312 \\
\hline & Both & 1.283 & 2.420 & 2.435 & 1.501 \\
\hline \multirow[t]{3}{*}{ ERF_SRF $\left(\mathrm{W} \mathrm{m}^{-2}\right)$} & India & -2.903 & -3.609 & -1.171 & -1.746 \\
\hline & China & -3.270 & -5.677 & -5.117 & -3.609 \\
\hline & Both & -4.580 & -7.837 & -5.158 & -4.768 \\
\hline \multirow[t]{3}{*}{ ERF_TOA $\left(\mathrm{W} \mathrm{m}^{-2}\right)$} & India & -1.623 & -0.594 & 0.082 & -0.505 \\
\hline & China & 1.177 & 2.219 & 3.362 & 1.871 \\
\hline & Both & 1.470 & 2.550 & 4.439 & 1.925 \\
\hline
\end{tabular}




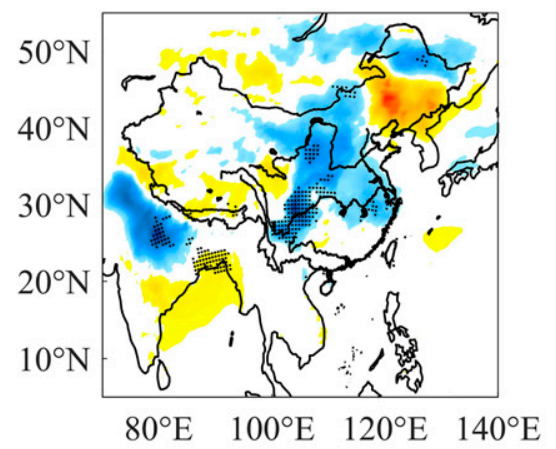

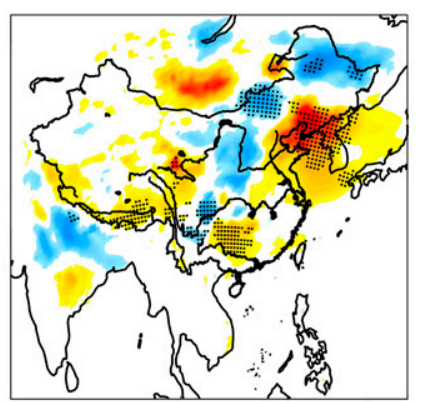

$80^{\circ} \mathrm{E} \quad 100^{\circ} \mathrm{E} \quad 120^{\circ} \mathrm{E} \quad 140^{\circ} \mathrm{E}$

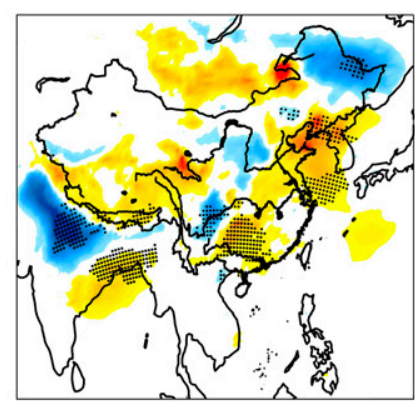

$80^{\circ} \mathrm{E} \quad 100^{\circ} \mathrm{E} \quad 120^{\circ} \mathrm{E} \quad 140^{\circ} \mathrm{E}$

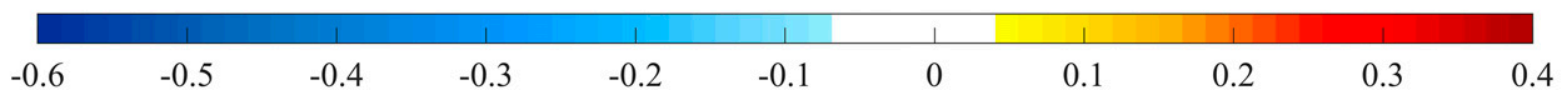

FIG. 5. Changes from Exp. 1 in the air temperature (K) averaged from the surface to $840 \mathrm{hPa}$ in response to (left) IDBC, (center) CNBC, and (right) the total BC. The black dots indicate the $90 \%$ confidence levels from the Student's $t$ test.

the same applies between the TAS responses to the total $\mathrm{BC}$ and those to IDBC in the Indian subcontinent.

Notably, the spatial distribution of the TAS response does not subsequently resemble that of the corresponding column burden (Fig. 3 vs Fig. 5) so an increase in the column burden can fail in inducing a linearly strengthened TAS response, which is termed as "nonlinearity" in Zhuang et al. (2019). For instance, the TAS response to IDBC is more significant than that to CNBC in certain areas, such as in the Sichuan Basin where the loading of IDBC is lower. Moreover, the TAS response to $\mathrm{BC}$ emissions from a single source region can exceed that from both regions in some regions of East Asia. For example, the significant regional cooling in central and southwestern China induced by IDBC and the strong regional warming in northern China induced by CNBC have both exceed the similar responses to the total $\mathrm{BC}$ in magnitude and affected area.

Figure 6 shows the responses of TAS and SWHR vertically. $\mathrm{BC}$ in East Asia mainly concentrates in the lower troposphere and decreases with altitude. Meanwhile, strong vertical mixing in summer can bring BC to the upper troposphere. As a result of the enhanced solar radiation absorption, the SWHR is substantially increased in high BC layers in the upper troposphere above altitudes less than $400 \mathrm{hPa}$ and in the lower troposphere below altitudes over $800 \mathrm{hPa}$, which is remarkable in the responses of the SWHR to $\mathrm{CNBC}$ and to the total $\mathrm{BC}$. In contrast, the positive responses in SWHR to IDBC are in the upper troposphere and less significant (less than $1.0 \times 10^{-6} \mathrm{~K} \mathrm{~s}^{-1}$ ) because $\mathrm{BC}$ transported from northern India mostly occupies the upper troposphere above altitudes with a pressure smaller than $400 \mathrm{hPa}$ and has a relatively low loading. The extra heating due to the $\mathrm{BC}$ direct effect is beneficial to an increase in air temperature. However, the area or layer with a strong SWHR increase or high $\mathrm{BC}$ loading is not necessarily associated with significant regional warming. For example, weak increases or even decreases in TAS induced by CNBC appear near the surface (below altitudes over $800 \mathrm{hPa})$ in the middle latitudes $\left(30^{\circ}-45^{\circ} \mathrm{N}\right)$ despite the strongly increased SWHR, which is also found in the near-surface SWHR response to the total $\mathrm{BC}$. The weak regional warming or even cooling results from the regional climate feedback. Other factors besides the direct BC effect, such as cloud cover and surface DRF, can also contribute to the TAS variation to a large extent (Zhang et al. 2009; Zanis et al. 2012; Zhuang et al. 2013, 2018; Das et al. 2015; Wang et al. 2015).

Figure 7 illustrates the cloud fraction (CF) anomalies in the lower troposphere. Generally, positive cloud cover anomalies correspond to negative TAS changes and vice versa. Therefore, the TAS responses (Fig. 5) are closely anticorrelated to the anomalies of CF. The CF in the low troposphere is decreased in the coastal areas in eastern China but is increased in northern India and northeastern China under the effect of the total BC, ranging from $-2.5 \%$ to $4 \%$. CNBC and IDBC each induce almost opposite CF responses in East Asia, which is consistent with the TAS responses. CNBC can cause decreased CF from northern to southeastern China, while the increased CF sporadically appears in central, northeastern, and southwestern China. A significant increase in CF surrounding the Hetao area $\left(39^{\circ} \mathrm{N}\right.$, $117^{\circ} \mathrm{E}$ ) of northern to central China was also illustrated in Zhuang et al. (2019). IDBC can induce relatively significant and coherent increases in $\mathrm{CF}$ from southwestern to central China. The $\mathrm{CF}$ responses to IDBC and CNBC both range from $-2 \%$ to $3 \%$.

The interaction between the direct effects of $\mathrm{BC}$ and $\mathrm{CF}$ is addressed in Zhuang et al. (2013), who suggested that the BC semidirect effect is conducive to the decreased $\mathrm{CF}$ and thus the increased TAS. Therefore, the reduction of CF in response to $\mathrm{CNBC}$ (or to the total $\mathrm{BC}$ ) in eastern China can partially result from the semidirect effect, which further enhances the regional warming. Another contributing factor is the circulation anomaly (Fig. 8). The feedback of the scattering aerosols (Fig. 13) may also favor the CF changes due to the indirect effect (Twomey 1974; Albrecht 1989).

\section{2) DYNAMIC FIELD RESPONSES TO BC}

In response to the perturbations of $\mathrm{BC}$, dynamic fields can also be affected once the thermal field has changed. Figures 8 and 9 present the changes in the atmospheric circulation 

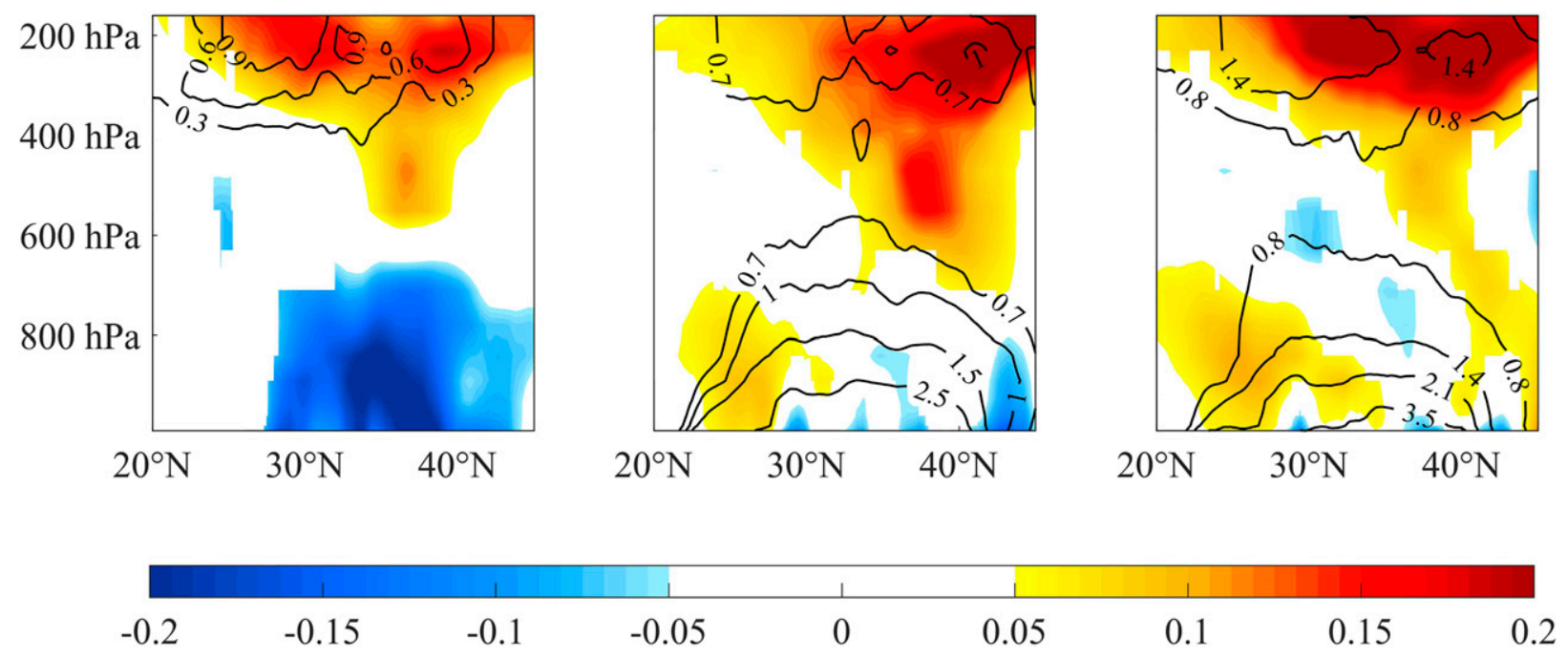

FIG. 6. Changes from Exp. 1 in the vertical air temperature (shaded; K) and shortwave heating rates (contours; $10^{-6} \mathrm{~K} \mathrm{~s}^{-1}$ ) in the altitude-latitude section averaged from $105^{\circ}$ to $125^{\circ} \mathrm{E}$ in response to (left) IDBC, (center) CNBC, and (right) the total BC. Differences that are not significant at $90 \%$ level (Student's $t$ test) are masked.

horizontally and vertically, respectively. CNBC induces a cyclonic anomaly in the areas from southwestern to northeastern China, which contributes to the southerly and southwesterly anomalies near $30^{\circ} \mathrm{N}$. A similar cyclonic anomaly is located farther east according to Zhuang et al. (2018), which is more advantageous to the East Asian summer monsoon development. The changes in these locations are possibly due to the less heating induced by lower loadings in the continent, and thus an anticyclonic anomaly with northerlies appears in southeastern China instead. In comparison, the IDBC-induced cyclonic anomaly appears weaker and is confined to southwestern China owing to the lower IDBC loading. Hence, the cyclonic anomalies caused by either CNBC or IDBC are significant in southwestern China with the confluence of southerly and northerly airflow, which is conducive to cloud formation and air temperature decrease (Figs. 5 and 7). Both IDBC and $\mathrm{CNBC}$ also induce convergence anomalies in the areas from northeastern India to the south slope of the QTP, and from northern to northeastern China with various strengths. The anticyclone in southeastern China is weaker and smaller, and accompanies the southwesterly wind anomalies in response to the total $\mathrm{BC}$ rather than to $\mathrm{CNBC}$ (Fig. 8). Therefore, the convergence is located farther east, with supplemental southerly wind anomalies from oceans. This result was also found in Zhuang et al. (2019), who suggested that the southerly or southwesterly anomalies could become more substantial in southern China if there are considerable BC loadings in East Asia. Vertically, an upward (downward) motion generally

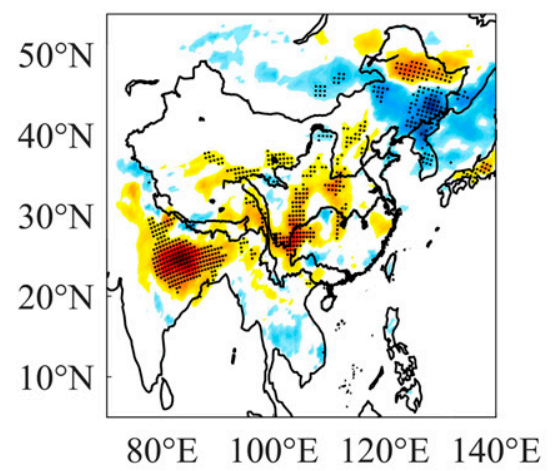

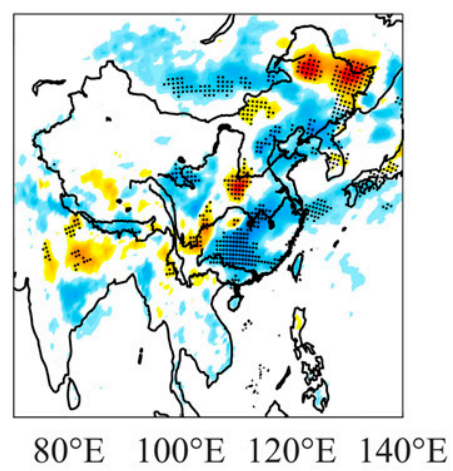

$80^{\circ} \mathrm{E} \quad 100^{\circ} \mathrm{E} \quad 120^{\circ} \mathrm{E} \quad 140^{\circ} \mathrm{E}$

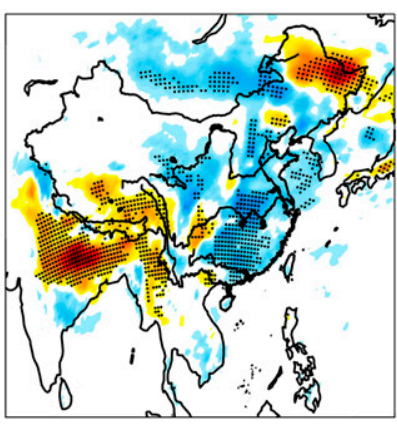

$80^{\circ} \mathrm{E} \quad 100^{\circ} \mathrm{E} \quad 120^{\circ} \mathrm{E} \quad 140^{\circ} \mathrm{E}$

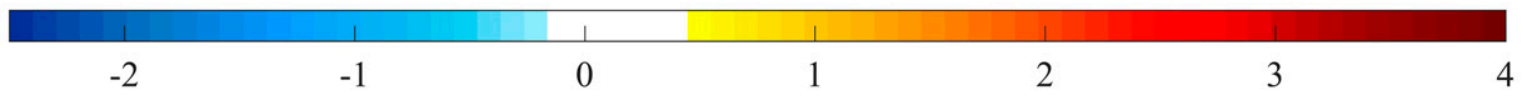

FIG. 7. Changes from Exp. 1 in the cloud fractions (\%) averaged from the surface to $840 \mathrm{hPa}$ in response to (left) IDBC, (center) CNBC, and (right) the total BC. The black dots in the figure indicate the $90 \%$ confidence levels from the Student's $t$ test. 


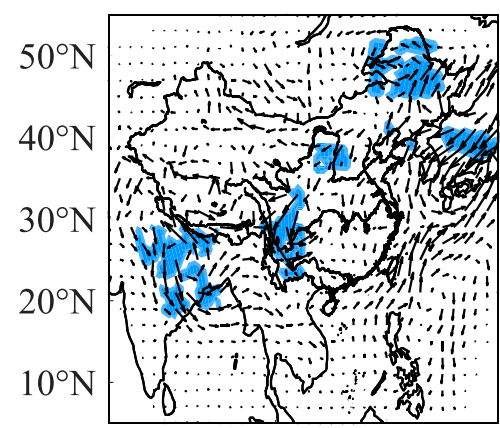

$80^{\circ} \mathrm{E} \quad 100^{\circ} \mathrm{E} \quad 120^{\circ} \mathrm{E} \quad 140^{\circ} \mathrm{E}$

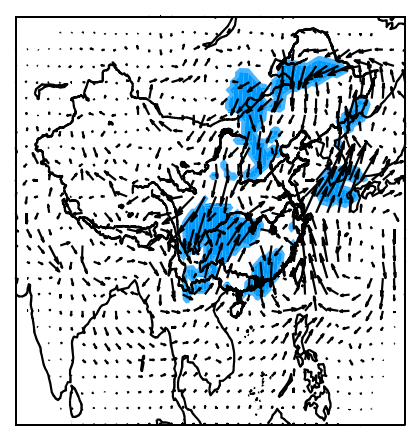

$80^{\circ} \mathrm{E} \quad 100^{\circ} \mathrm{E} \quad 120^{\circ} \mathrm{E} \quad 140^{\circ} \mathrm{E}$

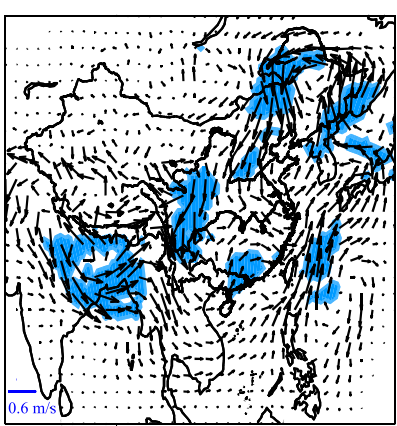

$80^{\circ} \mathrm{E} \quad 100^{\circ} \mathrm{E} \quad 120^{\circ} \mathrm{E} \quad 140^{\circ} \mathrm{E}$

FIG. 8. Changes from Exp. 1 in the wind fields at $840 \mathrm{hPa}$ (arrows; $\mathrm{m} \mathrm{s}^{-1}$ ) in response to (left) IDBC, (center) CNBC, and (right) the total BC. The blue shading indicates the $90 \%$ confidence level from the Student's $t$ test.

occurs where the atmosphere is strongly heated (cooled), which can further influence the meridional circulation. CNBC can result in an anticlockwise circulation anomaly in the middle to lower troposphere, coexisting with the confluence of southerly and northerly winds (Figs. 8 and 9), which further enhances the rising anomaly around $25^{\circ} \mathrm{N}$ where air temperature rises. Besides, southerly wind anomalies can increase considerably near the surface. Consistent with the horizontal circulation anomaly shown in Fig. 8, IDBC can cause a weaker response over East Asia than CNBC. Sinking motion appears around $35^{\circ} \mathrm{N}$ and further promotes the northerlies to lower latitudes where air temperature rarely decreases. A higher $\mathrm{BC}$ loading attributed to the total $\mathrm{BC}$ can further strengthen the anticlockwise circulation anomaly (more northerly extending to around $35^{\circ} \mathrm{N}$ ). Overall, the role of $\mathrm{CNBC}$ in changing the circulation field in East Asia is more notable. The circulation changes in the lower layers of the troposphere can affect moisture transport, as well as cloud and precipitation formation. Positive responses in $\mathrm{CF}$ over central China are weaker to the total $\mathrm{BC}$ than to $\mathrm{CNBC}$, which results from the southerlies moving farther east to the coastal areas. The moist centers appear mostly together with ascending motion due to $\mathrm{CNBC}$ and due to the total $\mathrm{BC}$ (Fig. 9), which favors the $\mathrm{CF}$ increase over East Asia.

\section{3) HYDROLOGICAL FIELD RESPONSES TO BC}

Thermal and dynamic responses in the atmosphere to the BC direct effect can lead to changes in the hydrological cycle (Figs. 10 and 11). Precipitation increases in northeastern China (over $0.20 \mathrm{~mm} \mathrm{day}^{-1}$ ), southwestern to central China (larger than $0.15 \mathrm{~mm} \mathrm{day}^{-1}$ ), and northern India (maximum exceeding $1.0 \mathrm{~mm}$ day $^{-1}$ ) under the impact of the total BC. Precipitation decreases from eastern India to the Bengal Bay and southeastern China (up to $-0.4 \mathrm{~mm} \mathrm{day}^{-1}$ ) and can extend to eastern China in the lower reaches of the Yangtze River. Either CNBC or IDBC can cause a more significant precipitation increase in central to northern China than the total BC. Local

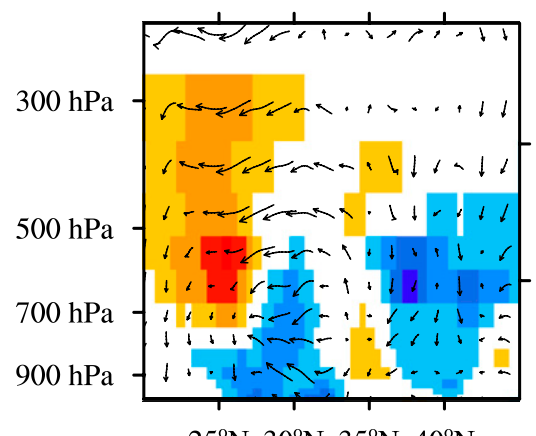

$25^{\circ} \mathrm{N} 30^{\circ} \mathrm{N} 35^{\circ} \mathrm{N} 40^{\circ} \mathrm{N}$

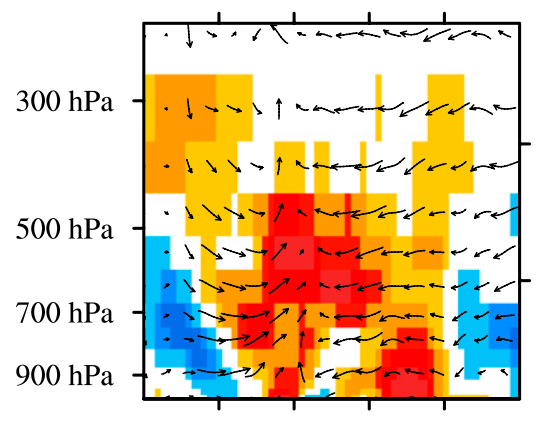

$25^{\circ} \mathrm{N} 30^{\circ} \mathrm{N} 35^{\circ} \mathrm{N} 40^{\circ} \mathrm{N}$

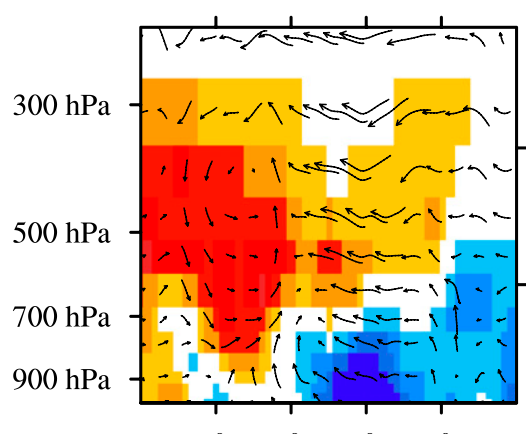

$25^{\circ} \mathrm{N} 30^{\circ} \mathrm{N} 35^{\circ} \mathrm{N} 40^{\circ} \mathrm{N}$

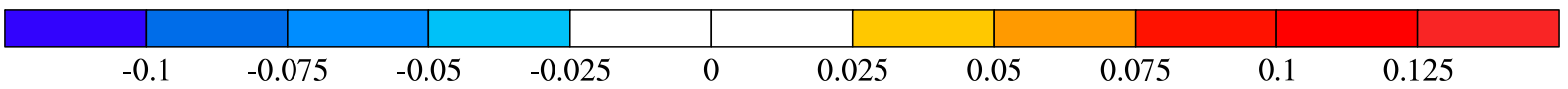

FIG. 9. Changes from Exp. 1 in the meridional circulation (arrows) and the specific humidity (shaded; $\mathrm{g} \mathrm{kg}^{-1}$ ) in the altitude-latitude section averaged from $105^{\circ}$ to $125^{\circ} \mathrm{E}$ in response to (left) IDBC, (center) CNBC, and (right) the total BC. For the reference arrow scale, 1 unit in the figure represents the wind anomaly in the horizontal wind $\left(\mathrm{m} \mathrm{s}^{-1}\right)$ and in the vertical motion $\left(-5 \times 10^{-3} \mathrm{~Pa} \mathrm{~s}^{-1}\right)$. 


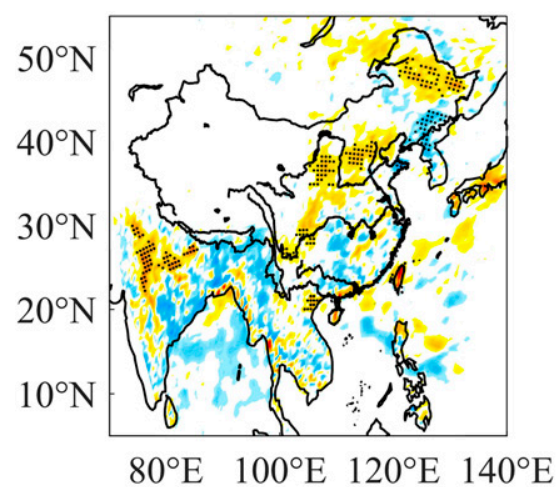

$80^{\circ} \mathrm{E} \quad 100^{\circ} \mathrm{E} \quad 120^{\circ} \mathrm{E} \quad 140^{\circ} \mathrm{E}$

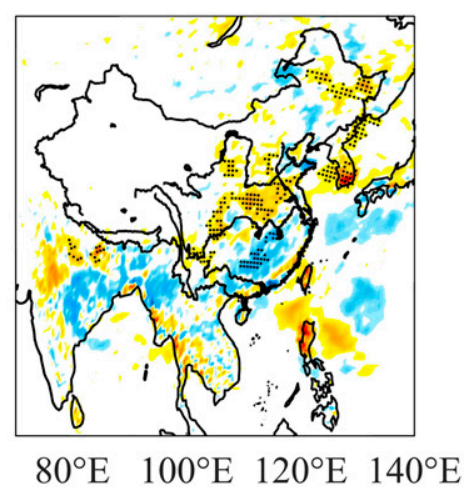

$80^{\circ} \mathrm{E} \quad 100^{\circ} \mathrm{E} \quad 120^{\circ} \mathrm{E} \quad 140^{\circ} \mathrm{E}$

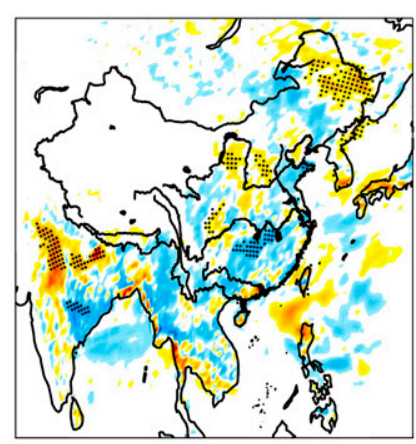

$80^{\circ} \mathrm{E} \quad 100^{\circ} \mathrm{E} 120^{\circ} \mathrm{E} 140^{\circ} \mathrm{E}$

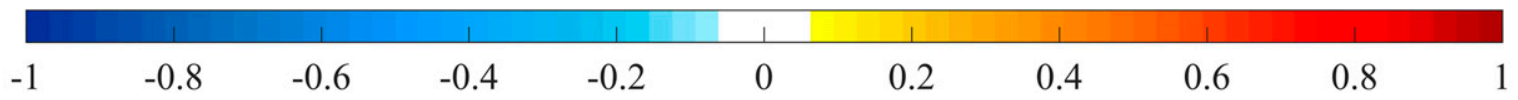

FIG. 10. Changes from Exp. 1 in the total precipitation $\left(\mathrm{mm} \mathrm{day}^{-1}\right)$ in response to (left) IDBC, (center) CNBC, and (right) the total BC. The black dots in the figure indicate the $90 \%$ confidence levels from the Student's $t$ test.

floods generally result from strengthened moisture transport and/or convergence anomalies, while local droughts are attributed to the weakened anomalies. On one hand, the convergence in northern India and northeastern China (Fig. 8) results in the elevated precipitation and liquid water path of clouds (Figs. 10 and 11) through the anticlockwise meridional circulation anomaly (Fig. 12). The confluence of the southerly and northerly wind anomalies in the areas from southwestern to central China (Fig. 8) can further increase rainfall in a similar way, which is less significant because the southerlies move eastward due to a stronger heating in land in response to the total BC than to CNBC or IDBC. On the other hand, the anticyclone over southeastern China (Fig. 8) accounts for the decreased liquid water path and rainfall (Figs. 10 and 11) to a large extent. Therefore, although the column burden is lower in southern China, the decreased rainfall can exceed that in northern China. Besides, the stronger semidirect effect of the higher BC loadings (Zhuang et al. 2013) of the total BC in central to northern China and the Bengal Bay can decrease the cloud liquid water path as well as the cloud cover more than that of CNBC or IDBC (Figs. 11 and 7). The responses in precipitation found in this study agree with some recent studies. Wang et al. (2009) stated that precipitation increases in the northern China but decreases in most areas south of the Yangtze River. Gu et al. (2006, 2010) suggested that the BC direct effect could increase precipitation in northeastern China and some coastal areas in southern China but decrease precipitation in central China. Meehl et al. (2008) indicated that rainfall has decreased over most of China but increased over South Asia. However, our results are different from those of $\mathrm{Gu}$ et al. (2016), who suggested that precipitation is significantly increased over southeastern China due to the dust heating effect, although rainfall in the coast of the Bay of Bengal and northwestern India is also found to increase in this study. Such contradictions in circulation and precipitation may be due to the different locations of the rainfall bands with respect to the heating sources and the circulation patterns associated with the precipitation (Wu et al. 2013; Gu et al. 2016). When the major rainfall band jumps northward in the second phase of the East Asian summer monsoon (from mid-June to early August), the changes in the precipitation depend on whether the monsoon is strong enough to enhance precipitation with warm and moist inflow in southeastern China regardless of the northward rainfall band. Therefore, the different rainfall amounts in southern China are attributed to the weaker monsoon due to the less heating on land [approximately $0.3 \mathrm{~K}$ lower than that in $\mathrm{Gu}$ et al. (2016)]. The BCinduced change in precipitation results from redistribution through influencing the circulation and cloud cover. The nonlinearity of regional climate responses to the $\mathrm{BC}$ loadings from different source regions is also reflected in the changes in precipitation, suggesting that precipitation changes over East Asia are reliant on the feedback of atmospheric thermodynamics fields rather than solely on BC loadings. Similar results were implied by Gu et al. (2016), who attributed the significant precipitation change to the circulation responses in areas where AOD difference is low. A comparison among Figs. 7, 8, and 10 suggests that both clouds and precipitation are affected by circulation perturbations. However, Fig. 11 suggests that cloud liquid path decreases more significantly than precipitation in some areas as a possible consequence of the BC semidirect effect (Zhuang et al. 2013).

Significant climate responses also appear in other areas. Regional climate responses to the total BC occur in northern India and northeastern China (at latitudes north of $45^{\circ} \mathrm{N}$ ), including the decreased TAS and increased $\mathrm{CF}$ and precipitation, as well as the cyclonic anomaly (Figs. 5, 6, 8, and 9). In northern India where BC loading is relatively lower, regional cooling covers most of the IGP. Meehl et al. (2008) suggested that the negative response results from substantial decreases in solar radiation at the surface and reflection of solar radiation in the upper layers, which is also shown in Fig. 4. However, the TAS 


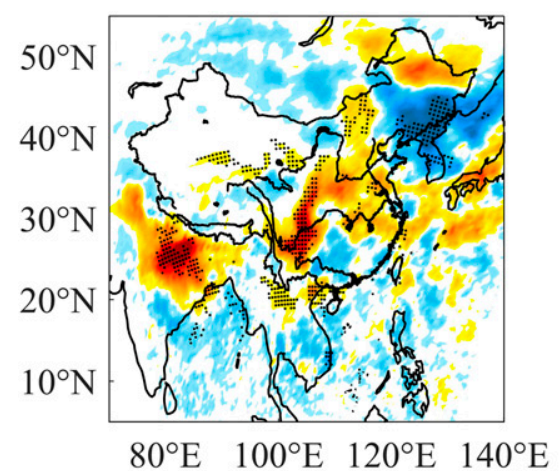

$80^{\circ} \mathrm{E} \quad 100^{\circ} \mathrm{E} \quad 120^{\circ} \mathrm{E} \quad 140^{\circ} \mathrm{E}$

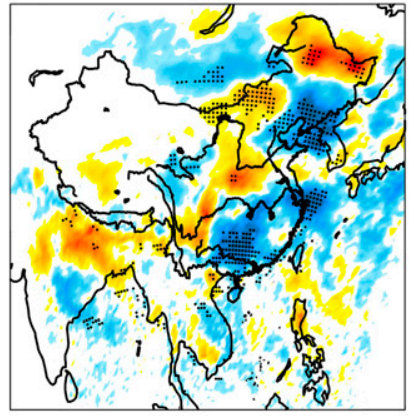

$80^{\circ} \mathrm{E} \quad 100^{\circ} \mathrm{E} \quad 120^{\circ} \mathrm{E} \quad 140^{\circ} \mathrm{E}$

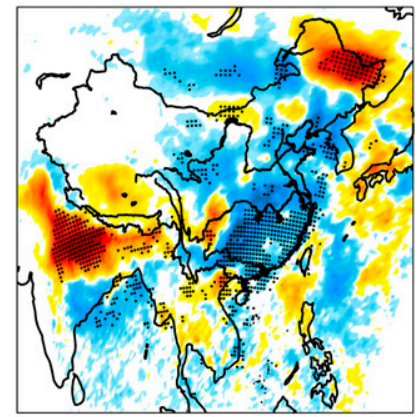

$80^{\circ} \mathrm{E} \quad 100^{\circ} \mathrm{E} \quad 120^{\circ} \mathrm{E}$

$-2$

$-1$

0

1

2

3

FIG. 11. Changes from Exp. 1 in the cloud liquid water path $\left(\mathrm{g} \mathrm{m}^{-2}\right)$ in response to (left) IDBC, (center) CNBC, and (right) the total BC. The black dots in the figure indicate the $90 \%$ confidence levels from the Student's $t$ test.

increases in the Bay of Bengal where the emission is extremely higher than that in northern India and the negative ERF at the surface is stronger. The difference between the responses in TAS may largely result from the circulation anomaly. The cyclone from the Bay of Bengal extending to the south slope of the QTP and the IGP brings about ascending motions, which further enhances the cloud formation and reduces the ERF at the TOA. However, stronger semidirect effects in the Bay of Bengal might inhibit the cloud and rainfall formation, and thus increase TAS.
An increase in TAS can lead to the cyclone and upward motion anomalies over the QTP (Fig. 5), which is referred to as an "elevated heat pump" effect (Lau et al. 2006). Both the BC effect of shortwave heating and the elevated topography north of India can bring about advection of warm air flowing northward and upward over the QTP, leading to the greatest warming near $45^{\circ} \mathrm{N}$ while northern India experiences consistently cooling in summer (Meehl et al. 2008). This can also contribute to the slight warming in northern China and the

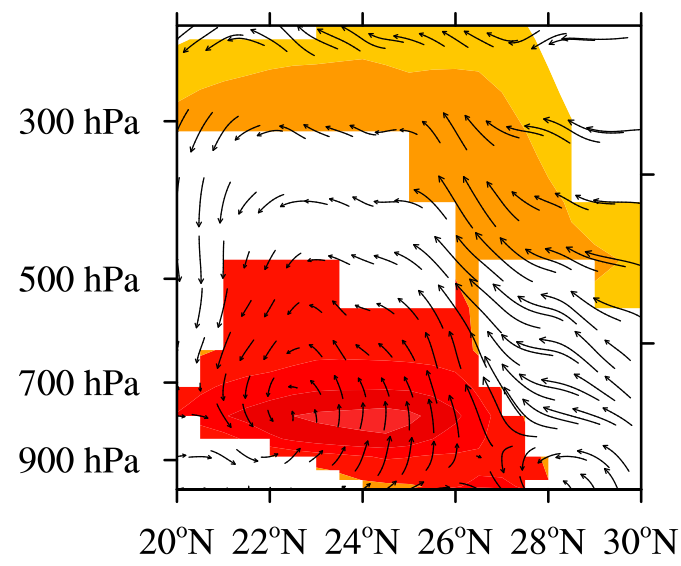

$20^{\circ} \mathrm{N} 22^{\circ} \mathrm{N} 24^{\circ} \mathrm{N} 26^{\circ} \mathrm{N} 28^{\circ} \mathrm{N} 30^{\circ} \mathrm{N}$

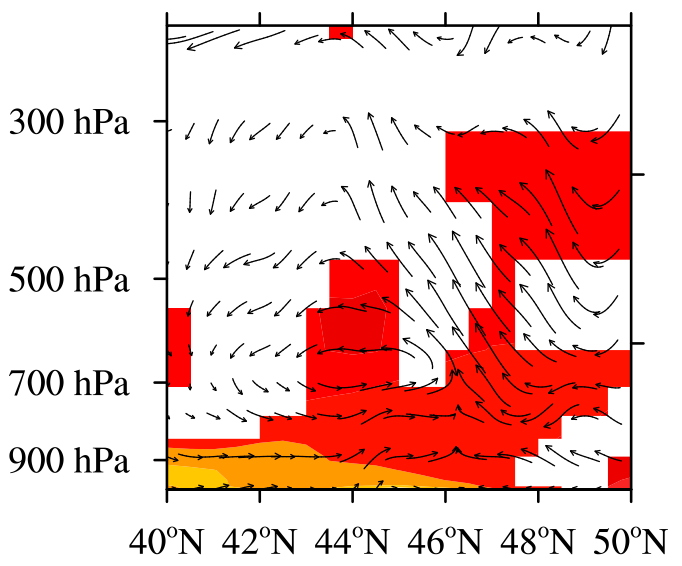

0.4

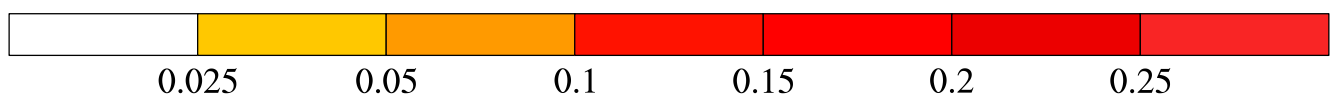

FIG. 12. Changes from Exp. 1 in the meridional circulation (arrows) the specific humidity (shaded; $\mathrm{g} \mathrm{kg}^{-1}$ ) in the altitude-latitude section averaged (left) from $80^{\circ}$ to $90^{\circ} \mathrm{E}$ and (right) from $120^{\circ}$ to $130^{\circ} \mathrm{E}$ in response to the total $\mathrm{BC}$. For the reference arrow scale, 1 unit in the figure represents the wind anomaly in the horizontal wind $\left(\mathrm{m} \mathrm{s}^{-1}\right)$ and in the vertical motion $\left(-5 \times 10^{-3} \mathrm{~Pa} \mathrm{~s}^{-1}\right)$. 

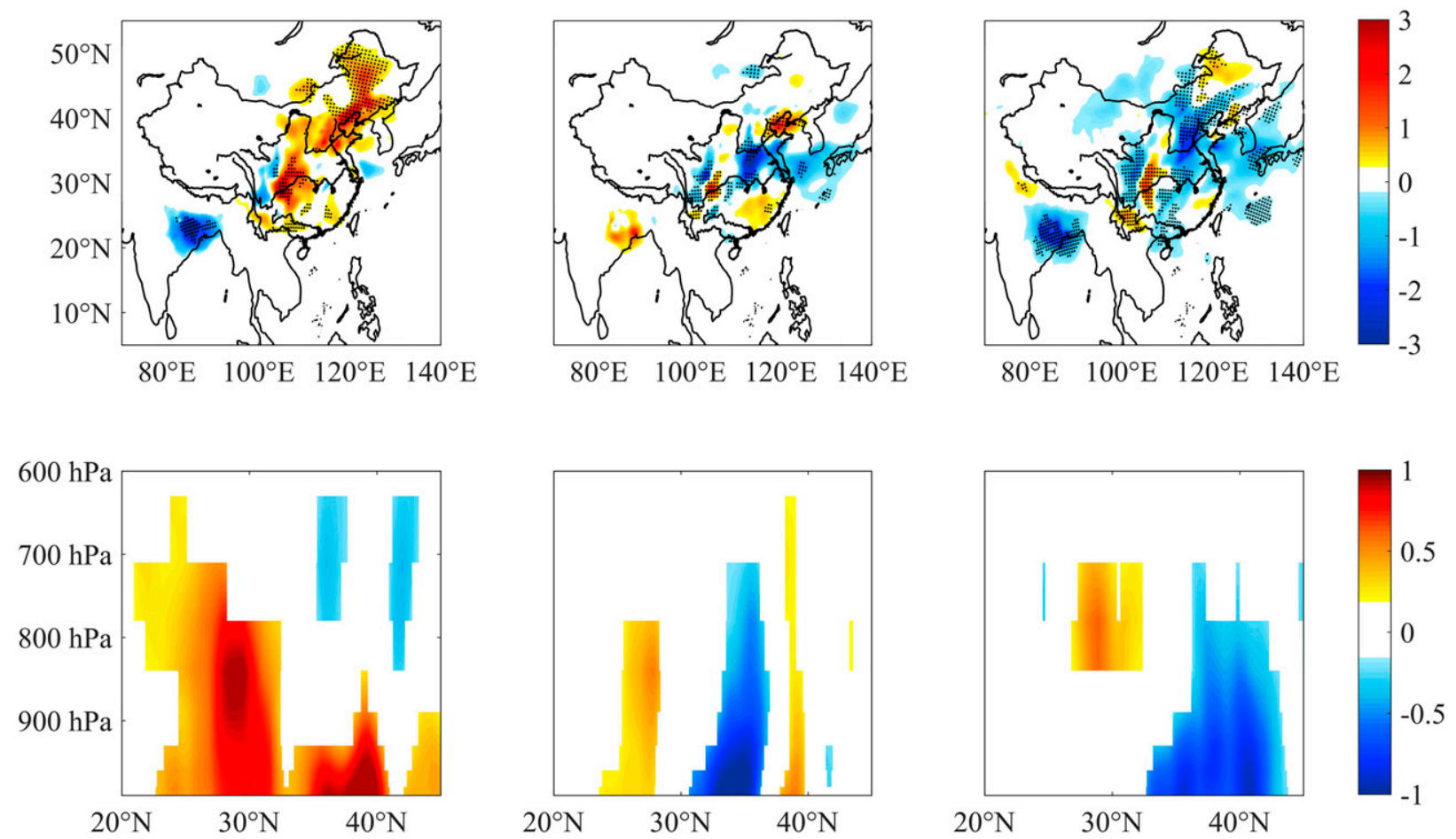

FIG. 13. Changes from Exp. 1 in the (top) surface and (bottom) vertical concentration $\left(\mu \mathrm{g} \mathrm{m}^{-3}\right)$ of sulfate in response to (left) IDBC, (center) CNBC, and (right) the total BC. The black dots in the top figure indicate the $90 \%$ confidence levels from the Student's $t$ test. Differences in the bottom figure that are not significant are masked.

Bohai Rim in response to IDBC. Previous studies implied that the anomalies can further alter the circulations in East Asia (Sun et al. 2012; Jiang et al. 2017; Tang et al. 2018; Zhuang et al. 2019). In northeastern China north of $45^{\circ} \mathrm{N}$, either CNBC or IDBC can lead to significant decreases in TAS and increases in $\mathrm{CF}$. Although the responses are similar, the reasons can be different. CNBC can bring about a cyclone anomaly, which is advantageous to cloud formation and temperature decrease. However, the convergence anomaly due to IDBC is relatively weaker. Therefore, the IDBC-induced changes in temperature and cloud are additionally affected by the accumulation of scattering aerosols in northeastern China where the loading of sulfate far exceeds that of BC (Fig. 13).

\section{d. Feedback of scattering aerosols}

The BC direct effect can lead to the redistribution of aerosols through altering the atmospheric thermal fields, dynamic circulations, and hydrological cycle. The responses of the sulfate concentration are shown in Fig. 13. The changes in the POC concentration are spatially similar to those in the sulfate concentration but with a smaller magnitude (not shown). The responses of aerosol loadings to IDBC are overall positive in East Asia, with the maximum of +0.7 and $+3.5 \mu \mathrm{g} \mathrm{m}^{-3}$ for POC and sulfate, respectively. Increased aerosol loadings appear mostly below altitudes over $800 \mathrm{hPa}$. The reasons for the positive responses are multifaceted. First, aerosols generally accumulate as precipitation decreases, especially over southern China (Fig. 10). Second, changes in atmospheric circulations can further affect the aerosol loadings. For instance, a sinking motion anomaly around $40^{\circ} \mathrm{N}$ could transport aerosols downward from the upper layers (Fig. 9), thus increasing aerosol loadings near the surface and decreasing the loadings in the upper troposphere. Third, surface cooling (Fig. 5) can enhance the atmospheric stability and inhibit the diffusion of aerosols from the surface to the upper troposphere, which favors the augmentation of aerosol loadings near the surface. Additionally, according to sensitivity analyses on the formation of aerosols in response to air temperature using ISORROPIA, Wang et al. (2015) suggested that decreases in air temperature are conducive to the formation of scattering aerosols, and accumulations of scattering aerosols can further enhance the regional cooling. Therefore, the surface cooling and the increased aerosol loadings in northeastern China might form a positive feedback. The aerosol level decreases in the Bengal Bay where the TAS rises and rainfall decreases, suggesting that the significant warming effect can inhibit sulfate formation to certain degrees in addition to the transport. The changes in aerosol loadings induced by CNBC are less remarkable. The most significant responses of aerosols in eastern China negatively correlate to precipitation (Fig. 10 vs Fig. 12), especially in the coastal areas. The strongest decrease is 0.6 and $3.0 \mu \mathrm{g} \mathrm{m}^{-3}$ for POC and sulfate, respectively. The increased loadings in the Sichuan Basin (the largest difference is +0.6 and $+3.0 \mu \mathrm{g} \mathrm{m}^{-3}$ for POC and sulfate, respectively) are associated with the regional cooling, convergence, and topography, all of which are unfavorable to the diffusion (Fig. 5). Thus, although the rainfall is significantly strengthened, the aerosol loadings can still be increased. 
TABLE 4. Regional means of the changes in climate variables and aerosol concentrations due to the direct effects of India, China, and two countries' BC in southern and northern China and over East Asia. [SC is southern China $\left(108^{\circ}-120^{\circ} \mathrm{E}, 20^{\circ}-30^{\circ} \mathrm{N}\right)$, $\mathrm{NC}$ is northern China $\left(108^{\circ}-120^{\circ} \mathrm{E}, 30^{\circ}-45^{\circ} \mathrm{N}\right)$, and EA is East Asia $\left(100^{\circ}-130^{\circ} \mathrm{E}, 20^{\circ}-50^{\circ} \mathrm{N}\right)$.

\begin{tabular}{lcrrr}
\hline \hline Climate variables/aerosol concentrations & Emission expt & SC & \multicolumn{1}{c}{ NC } & EA \\
\hline TAS $(\mathrm{K})$ & India & $-2.10 \times 10^{-2}$ & $-1.28 \times 10^{-1}$ & $-5.10 \times 10^{-2}$ \\
& China & $2.90 \times 10^{-2}$ & $-3.00 \times 10^{-2}$ & $2.20 \times 10^{-2}$ \\
& Both & $4.40 \times 10^{-2}$ & $9.00 \times 10^{-3}$ & $2.60 \times 10^{-2}$ \\
PR $\left(\mathrm{mm} \mathrm{day}^{-1}\right)$ & India & $-2.10 \times 10^{-2}$ & $4.00 \times 10^{-3}$ & $-7.00 \times 10^{-3}$ \\
& China & $-6.80 \times 10^{-2}$ & $6.00 \times 10^{-3}$ & $-1.10 \times 10^{-2}$ \\
& Both & $-6.70 \times 10^{-2}$ & $-3.00 \times 10^{-2}$ & $-2.80 \times 10^{-2}$ \\
$\mathrm{CF}(\%)$ & India & $1.57 \times 10^{-1}$ & $2.94 \times 10^{-1}$ & $1.29 \times 10^{-1}$ \\
& China & $-4.41 \times 10^{-1}$ & $5.30 \times 10^{-2}$ & $-7.60 \times 10^{-2}$ \\
& Both & $-3.08 \times 10^{-1}$ & $-2.84 \times 10^{-1}$ & $-1.36 \times 10^{-1}$ \\
POC $\left(\mu \mathrm{g} \mathrm{m}^{-3}\right)$ & India & $4.10 \times 10^{-2}$ & $4.30 \times 10^{-2}$ & $3.60 \times 10^{-2}$ \\
& China & $2.00 \times 10^{-3}$ & $-9.00 \times 10^{-3}$ & $2.00 \times 10^{-3}$ \\
$\mathrm{SO}_{4}^{2-}\left(\mu \mathrm{g} \mathrm{m}^{-3}\right)$ & Both & $-3.30 \times 10^{-2}$ & $-6.10 \times 10^{-2}$ & $-2.60 \times 10^{-2}$ \\
& India & $3.36 \times 10^{-1}$ & $4.58 \times 10^{-1}$ & $2.99 \times 10^{-1}$ \\
& China & $1.75 \times 10^{-1}$ & $-3.05 \times 10^{-1}$ & $-5.50 \times 10^{-2}$ \\
& Both & $-1.17 \times 10^{-1}$ & $-5.51 \times 10^{-1}$ & $-2.02 \times 10^{-1}$ \\
\hline
\end{tabular}

The responses to the total $\mathrm{BC}$ are generally similar to those to $\mathrm{CNBC}$ in East Asia despite some differences. The decreased loadings in northern and central China are magnified because of the northward convergence and corresponding upward motion over $35^{\circ}-45^{\circ} \mathrm{N}$ (Figs. 8 and 9). The increased loadings in southeastern China are further subdued under the influence of the different circulation, precipitation, and temperature feedbacks.

\section{e. Regional contributions}

Table 4 summarizes the changes in climate variables and aerosol concentrations due to the direct effects of IDBC, $\mathrm{CNBC}$, and the total $\mathrm{BC}$, which are assessed from the regional mean of air temperature below altitudes over $840 \mathrm{hPa}$, precipitation, and cloud fraction below altitudes over $840 \mathrm{hPa}$, as well as concentrations of POC and sulfate. The summaries are focused on three areas including southern China $\left(108^{\circ}-120^{\circ} \mathrm{E}\right.$, $\left.20^{\circ}-30^{\circ} \mathrm{N}\right)$, northern China $\left(108^{\circ}-120^{\circ} \mathrm{E}, 30^{\circ}-45^{\circ} \mathrm{N}\right)$, and East Asia $\left(100^{\circ}-130^{\circ} \mathrm{E}, 20^{\circ}-50^{\circ} \mathrm{N}\right)$. Generally, $\mathrm{BC}$ from each source region can lead to considerable regional climate changes over East Asia in summer. The total BC could reduce cloud amount ( $-0.136 \%$ on average), consequently leading to regional warming (maximum beyond $0.3 \mathrm{~K})$ and drought $\left(-0.028 \mathrm{~mm} \mathrm{day}^{-1}\right.$ on average) over East Asia. Stronger responses occur in southern China.

BC from each source region can lead to substantial and distinct regional climate changes over East Asia in summer. Under the direct effect of IDBC, significant changes in the dynamic filed and hydrological cycle can lead to the considerable accumulation of scattering aerosols over the entire East Asia (especially the sulfate loading near the surface, which is approximately an order of magnitude higher than BC), although the loading of IDBC is relatively low (Table 3). Thus, cloud optical depth and albedo (i.e., the "first" indirect or Twomey effect (Twomey 1974) are enhanced. Cloud radiation forcing is further enhanced because of expanded cloud cover extent and duration (i.e., the "second" indirect effect (Albrecht 1989). Consequently, the positive DRF at the TOA is further offset to certain degrees with a strongly negative DRF at the surface instead (Table 3). Liu et al. (2010) pointed out that the aerosol radiative effect of sulfate is more dominant than that of $\mathrm{BC}$ in decreasing precipitation over China. Also, the reduced TAS and precipitation can further contribute to the redistribution and accumulation of aerosols as a feedback. Therefore, the regional climate responses over East Asia due to IDBC may also depend on the significant scattering aerosol feedback. The BCinduced anomalies in the circulation field might play a vital role in such complicated climate responses. For example, heating in the atmosphere due to $\mathrm{BC}$ is unfavorable to the sulfate aerosol formation (Wang et al. 2015), while the substantial exchanges between warm and cold air masses can further overpass the warming tendency of BC (Sadiq et al. 2015). CNBC can lead to an increased TAS and decreased rainfall over East Asia with different climate responses in southern and northern China. For instance, responses of $\mathrm{CF}$ are negative over southern China but positive, although the magnitude is an order smaller over northern China. The two key reasons are illustrated in Figs. 7-9: the different responses in the atmospheric circulation along with the moist transport and the various contributions of the $\mathrm{BC}$ semieffect. One of our previous studies found that regional climate responses can be complicated and not linearly related to the regional column burdens or AODs, and the nonlinearity might be strengthened by the climate feedbacks such as the thermaldynamic feedback (Zhuang et al. 2019). The results here also suggest nonlinearity, because of which low IDBC loadings can induce comparable climate changes. The regional climate responses to IDBC also indicate that the aerosol feedbacks seem important to the strengthened nonlinearity.

Generally, CNBC plays a leading role in modulating climate in East Asia, with its dominant contribution to the magnitudes and distributions of the meteorological field responses in terms of TAS, CF, and precipitation. However, the direct effects of the total $\mathrm{BC}$ on the regional climate are far more complicated than a linear combination of the effects of CNBC and IDBC, mainly because of a more uniformly redistribution of BC. As 

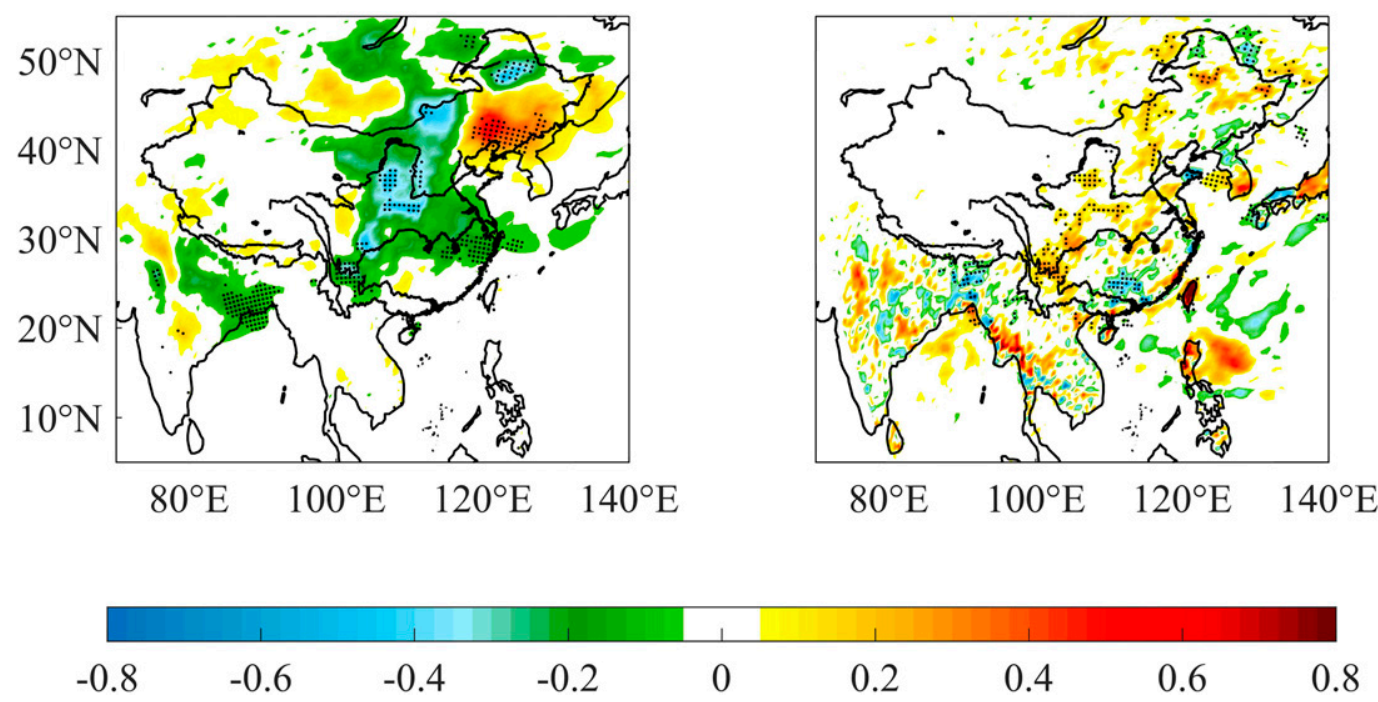

FIG. 14. Differences in the (left) air temperature (K) averaged from the surface to $840 \mathrm{hPa}$ and (right) total precipitation $\left(\mathrm{mm} \mathrm{day}^{-1}\right)$ between the changes in response to the total BC and the sum of the changes in response to IDBC and CNBC. The black dots in the figure indicate the $90 \%$ confidence levels from the Student's $t$ test.

illustrated in Fig. 14, the comparison of TAS and rainfall responses suggests that the responses to the total $\mathrm{BC}$ and a summing up in eastern to central China are especially inconsistent. One of our previous studies also found that the spatial variation in $\mathrm{BC}$ emissions can have significant influences on climate responses, especially in southern and eastern China (Zhuang et al. 2019). Further analyses and sensitivity tests should be conducted to address these issues.

Numerous studies of the direct effect of BC over East Asia has been conducted during the last two decades (e.g., Menon et al. 2002; Qian et al. 2003; Li et al. 2007; Zhang et al. 2009; Wang et al. 2015; Jiang et al. 2017), all of which suggested that $\mathrm{BC}$ is able to contribute to the local warming, hence offsetting the cooling effects of the total aerosols and enhancing the East Asia summer monsoon through strengthening the land-sea air temperature gradient. Therefore, the cloud formation and precipitation development are significantly boosted. The results of this study present similar regional climate responses to $\mathrm{BC}$, especially in China. However, different from previous studies, POC and sulfate are also taken into consideration with the contrast effects of scattering solar radiation. Therefore, the assessment of the regional climate responses is improved in this study. For instance, Wang et al. (2015) and Zhuang et al. (2018) suggested the regional mean of increased TAS over East Asia is 0.08 and $0.11 \mathrm{~K}$ during summer, respectively. Zhuang et al. (2019) suggested that TAS is increased as 0.082 and $0.127 \mathrm{~K}$ over southern and northern China, respectively. Overall, the changes in TAS estimated in our studies are relatively smaller than in other studies, especially in northern China.

\section{Conclusions}

Using a new version of the regional climate model RegCM4, we have studied the direct effect of BC aerosols over East Asia in summer in response to emissions from two different source regions, India and China. We have analyzed the associated effects on BC ERF and climate over East Asia in summer.

Overall, high BC column burdens appear in eastern, northern, and southwestern China, as well as northeastern India. The contribution of $\mathrm{CNBC}$ to the column burden in the study domain is up to $40 \%$, and that of IDBC is $25 \%$. BC usually brings about positive TOA ERF and negative surface ERF. Generally, the spatial variations of the BC ERF from different source regions resemble the corresponding variations in column burden. However, this is not always the case under the influences of surface albedo and cloud coverage. The regional mean column burden and surface ERF over East Asia are $1.501 \mathrm{mg} \mathrm{m}^{-2}$ and $-4.768 \mathrm{~W} \mathrm{~m}^{-2}$, respectively. The increased SWHR due to BC absorption is in favor of an increase in air temperature. Overall, air temperature in the lower troposphere increases by $0.026 \mathrm{~K}$ and precipitation decreases by $0.028 \mathrm{~mm} \mathrm{day}^{-1}$ in East Asia in response to the total BC.

We have further investigated how climate in East Asia responds to each of CNBC and IDBC individually. We found that $\mathrm{CNBC}$ can lead to regional warming along with cloud coverage reduction in most parts of East Asia. The dynamic responses occur correspondingly with the thermodynamics changes, including a cyclone anomaly from southwestern to northeastern China and an anticyclone circulation in southeastern China. Consequently, rainfall increases in central to northern China but decreases in southern China. Differently, IDBC especially perturbs TAS and presents significant regional cooling over East Asia despite the low column burden. The different responses result from a considerable increase in the sulfate loadings under the influence of the climate thermaldynamic feedback as a response to IDBC.

Although both IDBC and CNBC can lead to different but remarkable regional climate changes, it is found that $\mathrm{CNBC}$ plays a dominant role over East Asia as a result of the higher 
emission level and stronger climate feedback. The climate responses to the total $\mathrm{BC}$ are more complicated than a merely linear combination of those from the two countries individually, especially in eastern and central China. This finding reflects the nonlinearity between $\mathrm{BC}$ emissions and regional climate changes, to which more attention should be paid in future analyses. Overall, this study has provided a better understanding of the $\mathrm{BC}$ direct effect on the regional climate and a scientific reference for $\mathrm{BC}$ emission control strategies over East Asia.

There are a few limitations in this study that should be addressed in the future. First, the simulated period is only 11 years, limited by the numerical experiments that require substantial computational cost. Second, a fixed SST in the simulations might cause some biases in the land-sea temperature gradients (Sanap and Pandithurai 2015), which consequently results in the monsoonal climate changes (Lau et al. 2006). These biases can be partially reduced by using atmosphereocean coupling in future studies. Thus, the results represent the fast-atmospheric responses rather than the full impact excluding the SST responses, although they are relatively weak in a short-term simulation. The SST responses can be included in long-term simulations in the future to have a more comprehensive understanding of the climate impacts. Third, the indirect effects of BC, which could also significantly influence the regional climate (Zhuang et al. 2013), is not considered in the simulation due to their large uncertainties (Myhre et al. 2013).

Acknowledgments. This work was supported by the National Key R\&D Program of China and the National Natural Science Foundation of China (2019YFA0606803, 41675143, 2017YFC0209803, 41621005, 2014CB441203, 2016YFC0203303, 91544230).

Data availability statement. The source codes of and input data RegCM4 can be downloaded from http://clima-dods.ictp.it/ data/regcm4/. The NCEP reanalysis data (NNPR2) come from http://clima-dods.ictp.it/Data/RegCM_Data/NNRP2/. The sea surface temperature data (OISST) are available at https:// psl.noaa.gov/data/gridded/data.noaa.oisst.v2.html. The Asian anthropogenic emission inventory (MIX) is available at http:// www.meicmodel.org ( $\mathrm{Li}$ et al. 2017). The measurement of aerosols at the stations of the CMA Atmosphere Watch Network (CAWNET) is from Zhang et al. (2008, 2012). All data presented in this study are available from the corresponding author upon request.

\section{REFERENCES}

Albrecht, B. A., 1989: Aerosols, cloud microphysics, and fractional cloudiness. Science, 245, 1227-1230, https://doi.org/10.1126/ science.245.4923.1227.

Babu, S., and K. Moorthy, 2002: Aerosol black carbon over a tropical coastal station in India. Geophys. Res. Lett., 29, 2098, https://doi.org/10.1029/2002GL015662.

Bollasina, M., S. Nigam, and K.-M. Lau, 2008: Absorbing aerosols and summer monsoon evolution over South Asia: An observational portrayal. J. Climate, 21, 3221-3239, https://doi.org/ 10.1175/2007JCLI2094.1.
Bond, T. C., and Coauthors, 2013: Bounding the role of black carbon in the climate system: A scientific assessment. J. Geophys. Res. Atmos., 118, 5380-5552, https://doi.org/10.1002/JGRD.50171.

Boucher, O., and U. Lohmann, 1995: The sulfate-CCN-cloud albedo effect. Tellus, 47B, 281-300, https://doi.org/10.1034/ J.1600-0889.47.ISSUE3.1.X.

- , and Coauthors, 2013: Clouds and aerosols. Climate Change 2013: The Physical Science Basis, T. F. Stocker et al., Eds., Cambridge University Press, 571-657.

Cao, G. L., X. Y. Zhang, and F. C. Zheng, 2006: Inventory of black carbon and organic carbon emissions from China. Atmos. Environ., 40, 6516-6527, https://doi.org/10.1016/j.atmosenv. 2006.05.070.

Chang, L. S., and S. U. Park, 2004: Direct radiative forcing due to anthropogenic aerosols in East Asia during April 2001. Atmos. Environ., 38, 4467-4482, https://doi.org/10.1016/j.atmosenv. 2004.05.006.

Chen, C., and W. R. Cotton, 1987: The physics of the marine stratocumulus-caped mixed layer. J. Atmos. Sci., 44, 2951-2977, https://doi.org/10.1175/1520-0469(1987)044<2951:TPOTMS $>2$. $0 . \mathrm{CO} ; 2$.

Cook, J., and E. J. Highwood, 2004: Climate response to tropospheric absorbing aerosols in an intermediate general-circulation model. Quart. J. Roy. Meteor. Soc., 130, 175-191, https://doi.org/10.1256/ qj.03.64.

Das, S., S. Dey, and S. K. Dash, 2015: Impacts of aerosols on dynamics of Indian summer monsoon using a regional climate model. Climate Dyn., 44, 1685-1697, https://doi.org/10.1007/ s00382-014-2284-4.

,-- , and - , 2016: Direct radiative effects of anthropogenic aerosols on Indian summer monsoon circulation. Theor. Appl. Climatol., 124, 629-639, https://doi.org/10.1007/s00704015-1444-8.

Denis, B., R. Laprise, D. Caya, and J. Côté, 2002: Downscaling ability of one-way nested regional climate models: The BigBrother Experiment. Climate Dyn., 18, 627-646, https:// doi.org/10.1007/s00382-001-0201-0.

Ding, A. J., and Coauthors, 2016: Enhanced haze pollution by black carbon in megacities in China. Geophys. Res. Lett., 43, 2873-2879, https://doi.org/10.1002/2016gl067745.

Ding, Y.-H., and J. C. L. Chan, 2005: The East Asian summer monsoon: An overview. Meteor. Atmos. Phys., 89, 117-142, https://doi.org/10.1007/s00703-005-0125-z.

Emmons, L. K., and Coauthors, 2010: Description and evaluation of the model for ozone and related chemical tracers, version 4 (MOZART-4). Geosci. Model Dev., 3, 43-67, https://doi.org/ 10.5194/gmd-3-43-2010.

Forster, P., and Coauthors, 2007: Changes in atmospheric constituents and in radiative forcing. Climate Change 2007: The Physical Science Basis, S. Solomon et al., Eds., Cambridge University Press, 129-234.

Fountoukis, C., and A. Nenes, 2007: ISORROPIA II: A computationally efficient thermodynamic equilibrium model for $\mathrm{K}^{+}-$ $\mathrm{Ca}^{2+}-\mathrm{Mg}^{2+}-\mathrm{NH}_{4}^{+}-\mathrm{Na}^{+}-\mathrm{SO}_{4}^{2-}-\mathrm{NO}_{3}^{-}-\mathrm{Cl}^{-}-\mathrm{H}_{2} \mathrm{O}$ aerosols. Atmos. Chem. Phys., 7, 4639-4659, https://doi.org/10.5194/acp-7-4639-2007.

Fu, T.-M., and Coauthors, 2012: Carbonaceous aerosols in China: Top-down constraints on primary sources and estimation of secondary contribution. Atmos. Chem. Phys., 12, 2725-2746, https://doi.org/10.5194/acp-12-2725-2012.

Fu, Y., A. Tai, and H. Liao, 2016: Impacts of historical climate and land cover changes on fine particulate matter $\left(\mathrm{PM}_{2.5}\right)$ air quality in East Asia between 1980 and 2010. Atmos. Chem. Phys., 16, 10369-10383, https://doi.org/10.5194/acp-16-10369-2016. 
Gautam, R., and Coauthors, 2011: Accumulation of aerosols over the Indo-Gangetic plains and southern slopes of the Himalayas: Distribution, properties and radiative effects during the 2009 premonsoon season. Atmos. Chem. Phys., 11, 12 841-12 863, https:// doi.org/10.5194/acp-11-12841-2011.

Ghan, S. J., and Coauthors, 2001: A physically based estimate of radiative forcing by anthropogenic sulfate aerosol. J. Geophys. Res., 106, 5279-5293, https://doi.org/10.1029/2000JD900503.

Giles, D. M., and Coauthors, 2011: Aerosol properties over the Indo-Gangetic Plain: A mesoscale perspective from the TIGERZ experiment. J. Geophys. Res., 116, D18203, https:// doi.org/10.1029/2011JD015809.

Giorgi, F., and Coauthors, 2012: RegCM4: Model description and preliminary tests over multiple CORDEX domains. Climate Res., 52, 7-29, https://doi.org/10.3354/cr01018.

Gu, Y., K. N. Liou, Y. Xue, C. R. Mechoso, W. Li, and Y. Luo, 2006: Climatic effects of different aerosol types in China simulated by the UCLA general circulation model. J. Geophys. Res., 111, D15201, https://doi.org/10.1029/2005JD006312.

,-- W. Chen, and H. Liao, 2010: Direct climate effect of black carbon in China and its impact on dust storms. J. Geophys. Res., 115, D00K14, https://doi.org/10.1029/2009JD013427.

_ , Y. K. Xue, F. De Sales, and K. N. Liou, 2016: A GCM investigation of dust aerosol impact on the regional climate of North Africa and South/East Asia. Climate Dyn., 46, 23532370, https://doi.org/10.1007/s00382-015-2706-y.

Gultepe, I., and G. A. Isaac, 1999: Scale effects on averaging cloud droplet and aerosol number concentrations: Observations and models. J. Climate, 12, 1268-1279, https://doi.org/10.1175/ 1520-0442(1999)012<1268:SEOAOC >2.0.CO;2.

Guo, L., E. J. Highwood, L. C. Shaffrey, and A. G. Turner, 2013: The effect of regional changes in anthropogenic aerosols on rainfall of the East Asian summer monsoon. Atmos. Chem. Phys., 13, 1521-1534, https://doi.org/10.5194/acp-13-1521-2013.

Hansen, J., and Coauthors, 2005: Efficacy of climate forcings. J. Geophys. Res., 110, D18104, https://doi.org/10.1029/2005JD005776.

Horowitz, L. W., and Coauthors, 2003: A global simulation of tropospheric ozone and related tracers: Description and evaluation of MOZART, version 2. J. Geophys. Res., 108, 4784, https://doi.org/10.1029/2002jd002853.

Ji, Z., S. C. Kang, Z. Y. Cong, Q. G. Zhang, and T. D. Yao, 2015: Simulation of carbonaceous aerosols over the third pole and adjacent regions: Distribution, transportation, deposition, and climatic effects. Climate Dyn., 45, 2831-2846, https://doi.org/ 10.1007/s00382-015-2509-1.

Jiang, Y. Q., and Coauthors, 2017: Anthropogenic aerosol effects on East Asian winter monsoon: The role of black carboninduced Tibetan Plateau warming. J. Geophys. Res. Atmos., 122, 5883-5902, https://doi.org/10.1002/2016jd026237.

Kasoar, M., A. Voulgarakis, J.-F. Lamarque, D. T. Shindell, N. Bellouin, W. J. Collins, G. Faluvegi, and K. Tsigaridis, 2016: Regional and global temperature response to anthropogenic $\mathrm{SO}_{2}$ emissions from China in three climate models. Atmos. Chem. Phys., 16, 9785-9804, https://doi.org/10.5194/acp-169785-2016.

Kasten, F., 1969: Visibility forecast in the phase of pre-condensation. Tellus, 21, 631-635, https://doi.org/10.3402/tellusa.v21i5.10112.

Kiehl, J. T., and B. P. Briegleb, 1993: The relative roles of sulfate aerosols and greenhouse gases in climate forcing. Science, $\mathbf{2 6 0}$, 311-314, https://doi.org/10.1126/science.260.5106.311.

, J. J. Hack, G. B. Bonan, B. A. Boville, B. P. Briegleb, D. L. Williamson, and P. J. Rasch, 1996: Description of the NCAR Community Climate Model (CCM3). NCAR Tech.
Note NCAR/TN-420+STR, 152 pp., https://doi.org/10.5065/ D6FF3Q99.

_ T. L. Schneider, P. J. Rasch, M. C. Barth, and J. Wong, 2000: Radiative forcing due to sulfate aerosols from simulations with the National Center for Atmospheric Research community climate model version 3. J. Geophys. Res., 105, 1441-1457, https://doi.org/10.1029/1999JD900495.

Kristjánsson, J. E., 2002: Studies of the aerosol indirect effect from sulfate and black carbon aerosols. J. Geophys. Res., 107, 4246, https://doi.org/10.1029/2001JD000887.

Lal, D. M., S. D. Patil, H. N. Singh, S. D. Ghude, S. Tiwari, and M. K. Srivastava, 2013: Influence of aerosol on clouds over the Indo-Gangetic Plain, India. Climate Dyn., 41, 601-612, https:// doi.org/10.1007/s00382-013-1775-z.

Lau, K.-M., and K.-M. Kim, 2006: Observational relationships between aerosol and Asian monsoon rainfall, and circulation. Geophys. Res. Lett., 33, L21810, https://doi.org/10.1029/2006GL027546.

_- M.-K. Kim, and K.-M. Kim, 2006: Asian summer monsoon anomalies induced by aerosol direct forcing: The role of the Tibetan Plateau. Climate Dyn., 26, 855-864, https://doi.org/ 10.1007/s00382-006-0114-z.

Li, K., H. Liao, Y. H. Mao, and D. A. Ridley, 2016: Source sector and region contributions to concentration and direct radiative forcing of black carbon in China. Atmos. Environ., 124, 351366, https://doi.org/10.1016/j.atmosenv.2015.06.014.

Li, L., B. Wang, and T. Zhou, 2007: Contributions of natural and anthropogenic forcings to the summer cooling over eastern China: An AGCM study. Geophys. Res. Lett., 34, L18807, https://doi.org/10.1029/2007GL030541.

Li, M., and Coauthors, 2017: MIX: A mosaic Asian anthropogenic emission inventory under the international collaboration framework of the MICS-Asia and HTAP. Atmos. Chem. Phys., 17, 935-963, https://doi.org/10.5194/acp-17-935-2017.

Li, S., T. J. Wang, B. L. Zhuang, and Y. Han, 2009: Indirect radiative forcing and climatic effect of the anthropogenic nitrate aerosol on regional climate of China. Adv. Atmos. Sci., 26, 543-552, https://doi.org/10.1007/s00376-009-0543-9.

,-- , F. Solmon, B. L. Zhuang, H. Wu, M. Xie, Y. Han, and X. M. Wang, 2016: Impact of aerosols on regional climate in south and north China during strong/weak East Asian summer monsoon years. J. Geophys. Res. Atmos. 121, 4069-4081, https://doi.org/10.1002/2015JD023892.

Li, Z. Q., and Coauthors, 2016: Aerosol and monsoon climate interactions over Asia. Rev. Geophys., 54, 866-929, https:// doi.org/10.1002/2015RG000500.

Liou, K. N., and S. C. Ou, 1989: The role of cloud microphysical processes in climate: An assessment from a one-dimensional perspective. J. Geophys. Res., 94, 8599-8607, https://doi.org/ 10.1029/JD094iD06p08599.

Liu, H., L. Zhang, and J. Wu, 2010: A modeling study of the climate effects of sulfate and carbonaceous aerosols over China. Adv. Atmos. Sci., 27, 1276-1288, https://doi.org/10.1007/s00376-0109188-y.

Lohmann, U., Feichter, J., Penner, J., and Leaitch, R., 2000: Indirect effect of sulfate and carbonaceous aerosols: A mechanistic treatment. J. Geophys. Res. 105, 12 193-12 206, https://doi.org/10.1029/1999JD901199.

Lou, S., H. Liao, and B. Zhu, 2014: Impacts of aerosols on surfacelayer ozone concentrations in China through heterogeneous reactions and changes in photolysis rates. Atmos. Environ., 85, 123-138, https://doi.org/10.1016/j.atmosenv.2013.12.004.

Lu, Z., Q. Zhang, and D. G. Streets, 2011: Sulfur dioxide and primary carbonaceous aerosol emissions in China and India, 
1996-2010. Atmos. Chem. Phys., 11, 9839-9864, https://doi.org/ 10.5194/acp-11-9839-2011.

Manoj, M. G., P. C. S. Devara, P. D. Safai, and B. N. Goswami, 2011: Absorbing aerosols facilitate transition of Indian monsoon breaks to active spells. Climate Dyn., 37, 2181-2198, https://doi.org/10.1007/s00382-010-0971-3.

Martin, G. M., D. W. Johnson, and A. Spice, 1994: The measurements and parameterization of effective radius of droplets in warm stratocumulus clouds. J. Atmos. Sci., 51, 1823-1842, https://doi.org/10.1175/1520-0469(1994)051<1823:TMAPOE $>2.0$. $\mathrm{CO} ; 2$.

Meehl, G. A., J. M. Arblaster, and W. D. Collins, 2008: Effects of black carbon aerosols on the Indian monsoon. J. Climate, 21, 2869-2882, https://doi.org/10.1175/2007JCLI1777.1.

Menon, S., J. Hansen, L. Nazarenko, and Y. F. Luo, 2002: Climate effects of black carbon aerosols in China and India. Science, 297, 2250-2253, https://doi.org/10.1126/science.1075159.

Myhre, G., and Coauthors, 2013: Anthropogenic and natural radiative forcing. Climate Change 2013: The Physical Science Basis, T. F. Stocker et al., Eds., Cambridge University Press, 659-740.

Nair, V. S., F. Solmon, F. Giorgi, L. Mariotti, S. S. Babu, and K. K. Moorthy, 2012: Simulation of South Asian aerosols for regional climate studies. J. Geophys. Res., 117, D04209, https:// doi.org/10.1029/2011JD016711.

Pant, P., P. Hegde, U. C. Dumka, R. Sagar, S. K. Satheesh, K. K. Krishna Moorthy, A. Saha, and M. K. Srivastava, 2006: Aerosol characteristics at a high-altitude location in central Himalayas: Optical properties and radiative forcing. J. Geophys. Res., 111, D17206, https://doi.org/10.1029/2005JD006768.

Praveen, P. S., T. Ahmed, A. Kar, I. H. Rehman, and V. Ramanathan, 2012: Link between local scale BC emissions in the IndoGangetic plains and large scale atmospheric solar absorption. Atmos. Chem. Phys., 12, 1173-1187, https://doi.org/10.5194/acp12-1173-2012.

Qian, Y., F. Giorgi, Y. Huang, W. Chameides, and C. Luo, 2001: Regional simulation of anthropogenic sulfur over East Asia and its sensitivity to model parameters. Tellus, 53B, 171-191, https:/doi.org/10.3402/tellusb.v53i2.16573.

_, L. R. Leung, S. J. Ghan, and F. Giorgi, 2003: Regional climate effects of aerosols over China: Modeling and observation. Tellus, 55B, 914-934, https://doi.org/10.1046/J.1435-6935.2003.00070.X.

Qin, S. G., J. Tang, and Y. P. Wen, 2001: Black carbon and its importance in climate change studies [in Chinese]. Meteor. Mon., 27, 3-7, https://doi.org/10.3969/j.issn.1000-0526.2001.11.001.

Rai, K., A. K. Sarkar, and A. P. Mitra, 2002: Chemical characterization of aerosols at NPL, Delhi. IASTA Bull., 14, 155-158.

Randles, C. A., and V. Ramaswamy, 2008: Absorbing aerosols over Asia: A Geophysical Fluid Dynamics Laboratory general circulation model sensitivity study of model response to aerosol optical depth and aerosol absorption. J. Geophys. Res., 113, D21203, https://doi.org/10.1029/2008JD010140.

Sadiq, M., W. Tao, J. F. Liu, and S. Tao, 2015: Air quality and climate responses to anthropogenic black carbon emission changes from East Asia, North America and Europe. Atmos. Environ., 120, 262-276, https://doi.org/10.1016/j.atmosenv.2015.07.001.

Sanap, S. D., and G. Pandithurai, 2015: The effect of absorbing aerosols on Indian monsoon circulation and rainfall: A review. Atmos. Res., 164-165, 318-327, https://doi.org/10.1016/j.atmosres. 2015.06.002.

Shalaby, A., and Coauthors, 2012: Implementation and evaluation of online gas-phase chemistry within a regional climate model (RegCM-CHEM4). Geosci. Model Dev., 5, 741-760, https:// doi.org/10.5194/gmd-5-741-2012.
Solmon, F., N. Elguindi, and M. Mallet, 2012: Radiative and climatic effects of dust over West Africa, as simulated by a regional climate model. Climate Res., 52, 97-113, https://doi.org/ 10.3354/cr01039.

Song, F. F., T. J. Zhou, and Y. Qian, 2014: Responses of East Asian summer monsoon to natural and anthropogenic forcings in the 17 latest CMIP5 models. Geophys. Res. Lett., 41, 596-603, https://doi.org/10.1002/2013GL058705.

Sun, H., Z. Pan, and X. Liu, 2012: Numerical simulation of spatialtemporal distribution of dust aerosol and its direct radiative effects on East Asian climate. J. Geophys. Res., 117, D13206, https://doi.org/10.1029/2011JD017219.

Tang, Y. G., Y. X. Han, X. Y. Ma, and Z. H. Liu, 2018: Elevated heat pump effects of dust aerosol over Northwestern China during summer. Atmos. Res., 203, 95-104, https://doi.org/ 10.1016/j.atmosres.2017.12.004.

Tripathi, S. N., S. Dey, V. Tare, and S. K. Satheesh, 2005: Aerosol black carbon radiative forcing at an industrial city in northern India. Geophys. Res. Lett., 32, L08802, https://doi.org/10.1029/ 2005 GL022515.

Twomey, S., 1974: Pollution and the planetary albedo. Atmos. Environ., 8, 1251-1256, https://doi.org/10.1016/0004-6981(74)90004-3.

Wang, T. J., S. Li, Y. Shen, J. J. Deng, and M. Xie, 2010: Investigations on direct and indirect effect of nitrate on temperature and precipitation in China using a regional climate chemistry modeling system. J. Geophys. Res., 115, D00K26, https://doi.org/10.1029/2009JD013264.

—_, and Coauthors, 2015: The interactions between anthropogenic aerosols and the East Asian summer monsoon using RegCCMs. J. Geophys. Res. Atmos., 120, 5602-5621, https:// doi.org/10.1002/2014JD022877.

Wang, Z. L., P. W. Guo, and H. Zhang, 2009: A numerical study of direct radiative forcing due to black carbon and its effects on the summer precipitation in China (in Chinese). Climatic Environ. Res., 14, 161-171.

_ H. Zhang, and X. S. Shen, 2011: Radiative forcing and climate response due to black carbon in snow and ice. Adv. Atmos. Sci., 28, 1336-1344, https://doi.org/10.1007/s00376-011-0117-5.

Wilcox, E. M., 2012: Direct and semi-direct radiative forcing of smoke aerosols over clouds. Atmos. Chem. Phys., 12, 139-149, https://doi.org/10.5194/acp-12-139-2012.

Wu, J., C. B. Fu, Y. Xu, J. P. Tang, W. Wang, and Z. Wang, 2008: Simulation of direct effects of black carbon aerosol on temperature and hydrological cycle in Asia by a regional climate model. Meteor. Atmos. Phys., 100, 179-193, https://doi.org/ 10.1007/s00703-008-0302-y.

Wu, L. T., H. Su, and J. H. Jiang, 2013: Regional simulation of aerosol impacts on precipitation during the East Asian summer monsoon. J. Geophys. Res. Atmos., 118, 6454-6467, https://doi.org/10.1002/JGRD.50527.

Xie, X. D., T. J. Wang, Y. Xu, S. Li, B. L. Zhuang, and M. H. Wang, 2020: Effects of atmospheric aerosols on terrestrial carbon fluxes and $\mathrm{CO}_{2}$ concentrations in China. Atmos. Res., 237, 104859, https://doi.org/10.1016/j.atmosres.2020.104859.

Yang, Y., H. Wang, S. J. Smith, R. Zhang, S. Lou, Y. Qian, P.-L. Ma, and P. J. Rasch, 2018: Recent intensification of winter haze in China linked to foreign emissions and meteorology. Sci. Rep., 8, 2107, https://doi.org/10.1038/S41598-018-20437-7.

Yin, C. Q., T. J. Wang, F. Solmon, M. Mallet, F. Jiang, S. Li, and B. L. Zhuang, 2015: Assessment of direct radiative forcing due to secondary organic aerosol over China with a regional climate model. Tellus, 67B, 24634, https://doi.org/10.3402/tellusb. v67.24634. 
Yu, H., and Coauthors, 2013: A multimodel assessment of the influence of regional anthropogenic emission reductions on aerosol direct radiative forcing and the role of intercontinental transport. J. Geophys. Res. Atmos., 118, 700-720, https:// doi.org/10.1029/2012JD018148.

Zanis, P., C. Ntogras, A. Zakey, I. Pytharoulis, and T. Karacostas, 2012: Regional climate feedback of anthropogenic aerosols over Europe using RegCM3. Climate Res., 52, 267-278, https:// doi.org/10.3354/cr01070.

Zhang, H., Wang, Z. L., Guo, P. W., and Wang, Z. Z., 2009: A modeling study of the effects of direct radiative forcing due to carbonaceous aerosol on the climate in East Asia. Adv. Atmos. Sci., 26, 57-66, https://doi.org/10.1007/s00376-009-0057-5.

Zhang, X. Y., Y. Q. Wang, X. C. Zhang, W. Guo, and S. L. Gong, 2008: Carbonaceous aerosol composition over various regions of China during 2006. J. Geophys. Res., 113, D14111, https:// doi.org/10.1029/2007JD009525.

— - _ T. Niu, X. C. Zhang, S. L. Gong, Y. M. Zhang, and J. Y. Sun, 2012: Atmospheric aerosol compositions in China: Spatial/ temporal variability, chemical signature, regional haze distribution and comparisons with global aerosols. Atmos. Chem. Phys., 12, 779-799, https://doi.org/10.5194/acp-12-779-2012.

Zhao, B., S. X. Wang, X. Y. Dong, J. D. Wang, L. Duan, X. Fu, J. M. Hao, and J. Fu, 2013: Environmental effects of the recent emission changes in China: Implications for particulate matter pollution and soil acidification. Environ. Res. Lett., 8, 024031, https://doi.org/10.1088/1748-9326/8/2/024031.
Zhou, Y., A. N. Huang, J. Jiang, and M. La, 2014: Modeled interaction between the subseasonal evolving of the East Asian summer monsoon and the direct effect of anthropogenic sulfate. J. Geophys. Res. Atmos., 119, 1993-2016, https://doi.org/ 10.1002/2013JD020612.

Zhuang, B. L., T. J. Wang, and S. Li, 2009: First indirect radiative forcing of black carbon aerosol and its effect on regional climate of China. Plateau Meteor., 28, 1095-1103.

— L Liu, L., Shen, F. H., Wang, T. J., and Han, Y., 2010: Semidirect radiative forcing of internal mixed black carbon cloud droplet and its regional climatic effect over China. J. Geophys. Res., 115, D00K19, https://doi.org/10.1029/2009JD013165.

—, Q. Liu, T. J. Wang, C. Q. Yin, S. Li, M. Xie, F. Jiang, and H. T. Mao, 2013: Investigation on semi-direct and indirect climate effects of fossil fuel black carbon aerosol over China. Theor. Appl. Climatol., 114, 651-672, https://doi.org/10.1007/s00704013-0862-8.

— of urban aerosols in Nanjing, China. Atmos. Environ., 83, 4352, https://doi.org/10.1016/j.atmosenv.2013.10.052.

—, S. Li, T. J. Wang, J. Liu, P. L. Chen, H. M. Chen, M. M. Li, and M. Xie, 2018: Interaction between the black carbon aerosol warming effect and East Asian monsoon using RegCM4. J. Climate, 31, 9367-9388, https://doi.org/10.1175/JCLI-D-17-0767.1.

_ , and Coauthors, 2019: The direct effects of black carbon aerosols from different source sectors in East Asia in summer. Climate Dyn., 53, 5293-5310, https://doi.org/10.1007/s00382-019-04863-5. 